Aus der Klinik für Psychosomatische Medizin und Psychotherapie

(Leitung: Prof. Dr. med. C. Herrmann-Lingen)

im Zentrum Psychosoziale Medizin

der Medizinischen Fakultät der Universität Göttingen

\title{
The association between stress and blood pressure in a sample from the German Health Interview and Examination Survey for Adults (DEGS1)
}

\author{
INAUGURAL-DISSERTATION \\ zur Erlangung des Doktorgrades \\ der Medizinischen Fakultät der \\ Georg-August-Universität zu Göttingen
}

\author{
vorgelegt von \\ Lina Hassoun \\ aus \\ Latakia, Syrien
}

Göttingen 2015 
Dekan: $\quad$ Prof. Dr. rer. nat. H. K. Kroemer

I. Berichterstatter: Prof. Dr. Thomas Meyer

II. Berichterstatter: Prof. Dr. Rolf Wachter

III. Berichterstatterin: Prof. Dr. Margarete Schön

Tag der mündlichen Prüfung: 29.07.2015 


\section{Table of Contents}

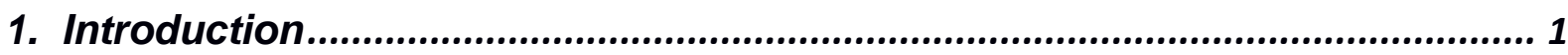

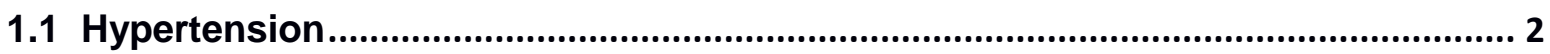

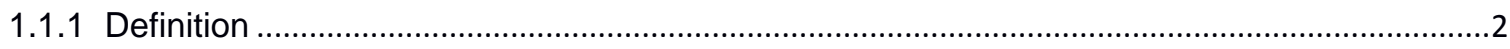

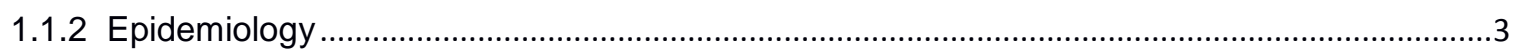

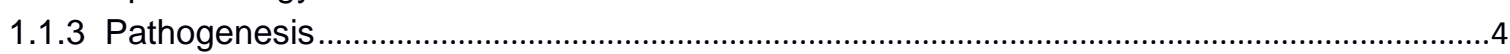

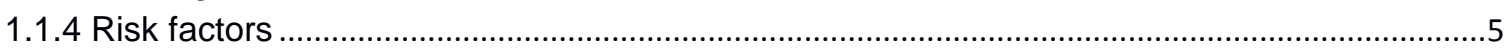

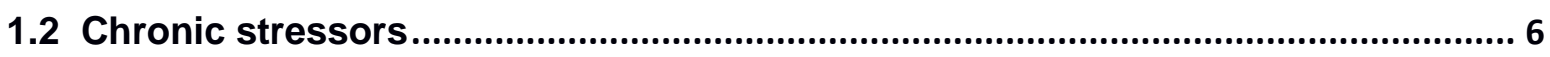

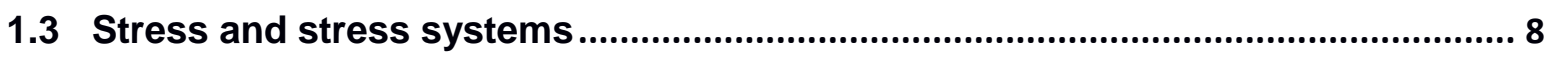

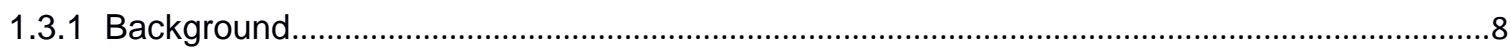

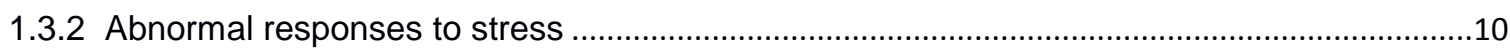

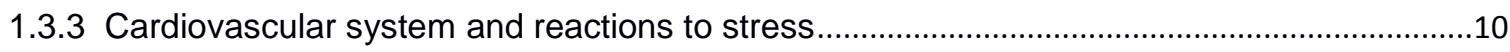

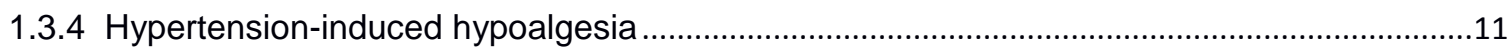

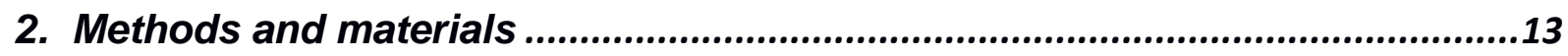

2.1 DEGS1 study

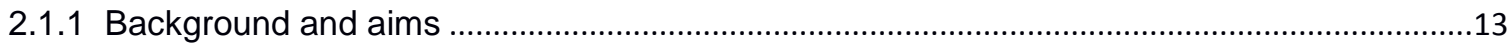

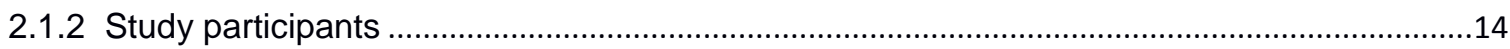

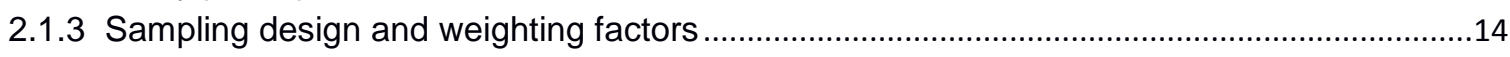

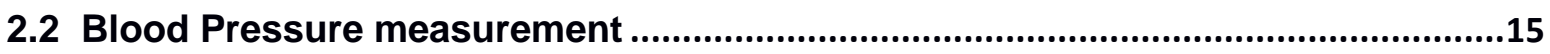

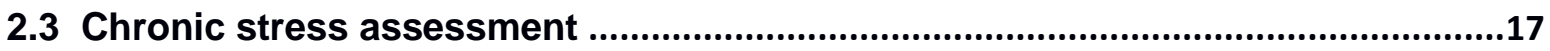

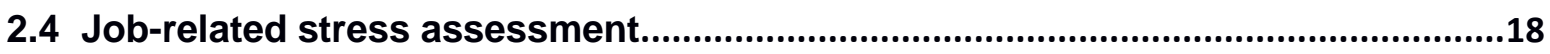

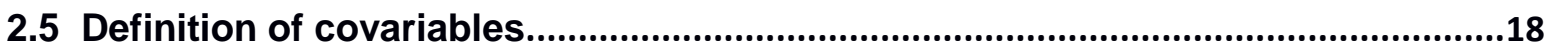

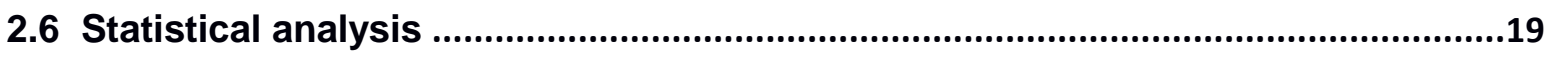

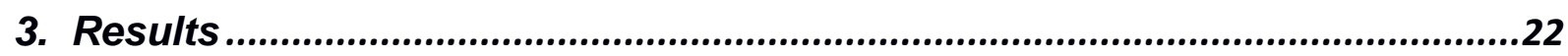

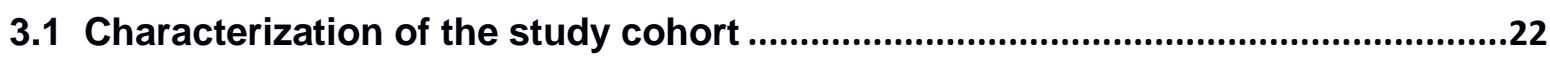

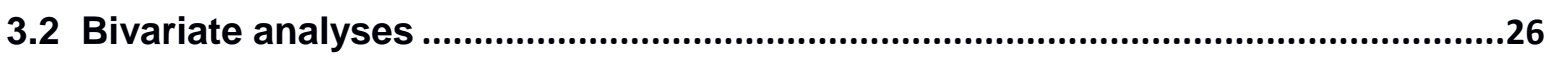

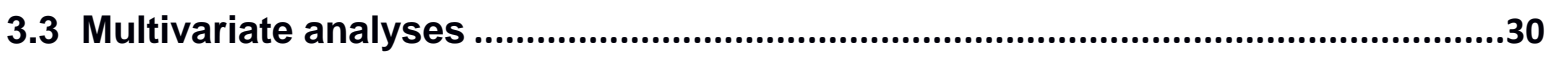

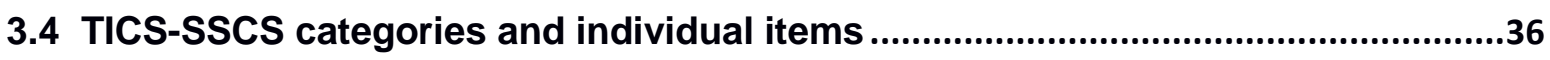

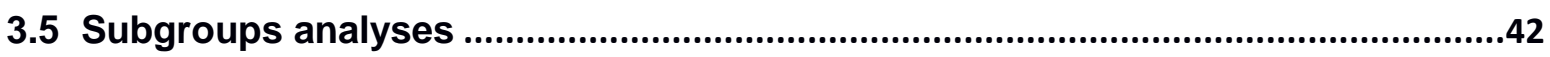

3.6 Analysis of the repeated measurements of blood pressure ................................44

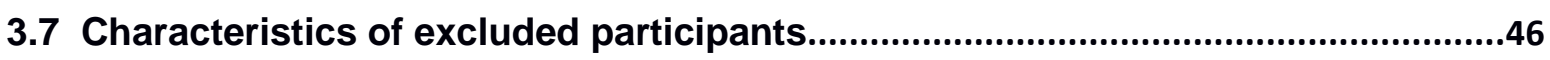

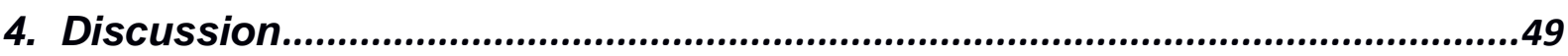

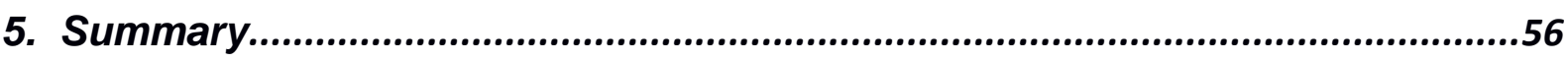

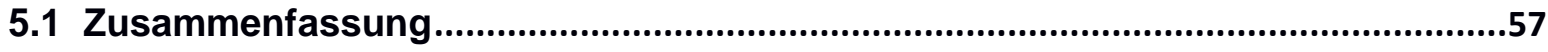

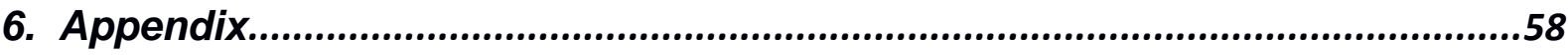

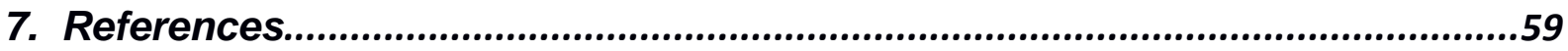




\section{Introduction}

Elevated arterial blood pressure is a worldwide highly prevalent and independent risk factor for morbidity and mortality which contributes to the development of coronary heart disease and renal insufficiency, as well as stroke. Because of its many known complications as well as its evident direct relationship to the overall mortality from cardiovascular events (Lewington et al. 2002), much efforts were devoted to understand the etiologies of hypertension, and various factors were suggested to play a potential causative role in its development.

Stress exposure has long been proposed to contribute to the pathogenesis of cardiovascular diseases and hypertension. While the effect of acute stress is well established (Rozanski et al. 1999) as it causes a transient elevation in blood pressure and may trigger cardiovascular events, the effect of chronic stress on the other hand is less conclusive. However, accumulated evidence tends to show that both psychosocial and physical stress contribute to hypertension (Sparrenberger et al. 2009). In the context of an acute stressor, blood pressure elevation is considered as a part of a physiological response, while for persistent or recurrent stress exposure a maladaptive response pattern could lead to the development of different diseases, such as hypertension and atherosclerosis (Bao et al. 2008). However, it has been emphasized that individual differences in perceiving and reacting to stress have a great impact on its medical consequences (McEwen 1998).

Different stressors were studied for their association with hypertension, such as exposure to traumatic experiences, living in high crime areas, and job stresses. All of these stressors as well as others were defined and measured using various instruments. It is noteworthy that different results were obtained from various studies linking stress exposure to hypertension, which ranged from positive association to no or even to an inverse association (Nyklícek et al. 1996). These discrepancies were explained by methodological differences focusing on the fact that different scales were used to assess stress. In general, a positive association between stress exposure and blood pressure level was shown in studies that used objective measures of stress, while contradictory results were found in studies using measures of self-reported stress (Nyklícek et al. 1996). Moreover, it was found that hypertensive patient's appraisal of stressors is less than that found in normotensives (Sapira et al. 1971; Nyklícek et al. 2001). This unexpected inverse correlation was 
found also in studies concerned with the association between blood pressure and different aspects of mental well-being; for example, some recent trials showed that lower blood pressure is associated with depression and anxiety (Hildrum et al. 2007), while elevated blood pressure was found to be correlated with better quality of life in German adolescents (Berendes et al. 2013).

In the present post-hoc analysis of the nationwide representative German Health Interview and Examination Survey for Adults (DEGS1), I investigated for possible correlations between blood pressure level and two different scales of stress, namely the Trier Inventory for the assessment of chronic stress (TICS-SSCS) and the Job Index, after adjusting for different potential confounders. This approach allows for testing the importance and consistency of the above mentioned correlations.

Taking into consideration that in series of consecutive blood pressure readings the first reading is usually the highest for unknown reasons (Pickering et al. 2005), I will in this post-hoc study also search for possible interactions between the pattern of changes in blood pressure across consecutive measurements on one hand and selfreported stress on the other hand.

\subsection{Hypertension}

\subsubsection{Definition}

The seventh report of the Joint National Committee (JNC 7) published in the year 2003 suggested the following definitions:

- Normal blood pressure: systolic $<120 \mathrm{mmHg}$ and diastolic $<80 \mathrm{mmHg}$

- Prehypertension: systolic 120 to $139 \mathrm{mmHg}$ or diastolic 80 to $89 \mathrm{mmHg}$

- Hypertension:

Stage 1: systolic 140 to $159 \mathrm{mmHg}$ or diastolic 90 to $99 \mathrm{mmHg}$

Stage 2: systolic $\geq 160$ or diastolic $\geq 100 \mathrm{mmHg}$.

It was emphasized that these definitions should be based on the average of two or more readings of blood pressure that were measured following an established protocol, at each of two or more visits after an initial screen (Chobanian et al. 2003). 
For adults, who are taking antihypertensive medications or have an acute illness, these definitions cannot be applied.

\subsubsection{Epidemiology}

Hypertension is a worldwide highly prevalent public-health issue which is expected to be even more prevalent in the coming decades. According to a review by Kearney and colleagues (2005), the prevalence of hypertension in adult populations in 2000 was about $26.4 \%$ ( $26.6 \%$ of men and $26.1 \%$ of women), and this prevalence is expected to reach $29.2 \%$ (29.0\% of men and $29.5 \%$ of women) by 2025 . The number of adults with hypertension in 2025 is predicted to reach a total of 1.56 billion. This predicts an increase of more than $50 \%$ of the total number of adults with hypertension in 2000 which was estimated to be 972 million (Kearney et al. 2005).

This high prevalence is of great importance because hypertension is worldwide associated with a high burden of both morbidity and mortality, and it was reported that about $13.5 \%$ of the global total premature deaths were related to high blood pressure (Lawes et al. 2008). In order to get a comprehensive idea about disease burden, measuring the prevalence of premature mortality should be combined with the concept of disability-adjusted life years (DALYs). DALYs is a composite measure, which can be defined as the sum of years lived with disability and years of life lost because of early deaths (Murray et al. 2012). It was estimated that hypertension is responsible for about $6 \%$ of the global total DALYs, in addition to that, about $47 \%$ of ischemic heart disease and $54 \%$ of stroke worldwide were also linked to elevated blood pressure (Lawes et al. 2008). However, it should be mentioned that while about half of the cases were in hypertensive patients, more importantly the rest were found in people who had elevated blood pressure to less degrees.

A strong and direct relation was found between the level of blood pressure and both vascular and overall mortality, which was not only restricted to the hypertension range, but could be detected with values down to at least 115/75 mmHg (Lewington et al. 2002). There is evidence that interventions for reduction of blood pressure such as reducing salt intake can eventually reduce the risk of non-communicable diseases (Beaglehole et al. 2011). Even small population-wide reductions in blood pressure could have great impact on public health (Whelton et al. 2002). For example, 
according to an analysis based on the Framingham Heart Study experience in a cohort of white US residents aging 35 to 64 years, a population-wide minor reduction in the average of diastolic blood pressure $(2 \mathrm{mmHg})$ would lead to a $6 \%$ decrease in the coronary heart disease risk, and a $14 \%$ decrease in the risk of stroke and transient ischemic attacks (Cook et al. 1995). According to these reports, not only hypertension should be taken into consideration, but treatment and preventive strategies should be extended to include also blood pressure levels within the normal range.

\subsubsection{Pathogenesis}

In most patients with hypertension, it is not possible to identify a single reversible cause for their pathologically elevated blood pressure, and for these cases the term primary hypertension is used. In $5 \%$ to $10 \%$ of the cases, a more discrete pathogenesis can be identified, and for such cases the term secondary hypertension is reserved.

The pathogenesis of primary, or essential, hypertension is poorly understood. Many mechanisms have been implicated to be involved in the pathogenesis of essential hypertension, including between others the following:

- Neural mechanisms: High sympathetic neural activity associated with increased beta-adrenergic responsiveness was frequently reported in patients with primary hypertension (Victor and Shafiq 2008).

- Hormonal mechanisms: Both excess in mineralocorticoid and increased angiotensin II activity are considered to be important mechanisms in the development of hypertension (Victor 2012).

- Renal mechanisms: Decreased adult nephron mass may be involved in the development of hypertension, which may be attributed to genetic factors, developmental disturbance (e.g., infections, hypoxia, drugs), and environmental factors (e.g., malnutrition, infections) (Victor 2012). 


\subsubsection{Risk factors}

In light of the well-known blood pressure-related morbidity and mortality, a lot of efforts were devoted to uncover factors that contribute to the development of hypertension. The development of hypertension can be explained by the interaction between environmental and behavioral exposures in addition to genetic background (Sparrenberger et al. 2009), and a variety of risk factors have been shown to be associated with essential hypertension:

- Ethnicity: Hypertension in blacks is found to be both more frequent and more severe than in whites (Carson et al. 2011).

- Family history: Diagnosis of parental hypertension is strongly and independently associated with higher levels of blood pressure and the development of hypertension (Wang et al. 2008).

- Salt intake: High sodium intake is associated with an increased risk for the development of hypertension, moreover sodium restriction was found to lower blood pressure (He and MacGregor 2010).

- Alcohol intake: A clear association is reported between excessive alcohol consumption and the development of hypertension (Marchi et al. 2014).

- Obesity and overweight are both well-studied risk factors for hypertension, and modification in diet can lower blood pressure (Forman et al. 2009).

- Lack of physical activity is reported to increase the risk for hypertension, and physical exercise is one of the important life style modifications that can effectively lower blood pressure (Carnethon et al. 2010).

- Dyslipidemia: An abnormal lipid profile is an independent risk factor of hypertension regardless of obesity and overweight (de Simone et al. 2006).

- Many studies suggested a role of fructose as a risk factor for hypertension (Jalal et al. 2010), while other trials suggest that it does not raise blood pressure (Ha et al. 2012).

- Vitamin D deficiency is related to higher risk of hypertension development (Burgaz et al. 2011). 
- Psychosocial factors were proposed to contribute to the etiology of essential hypertension: certain personality traits, such as hostility, are more commonly associated with hypertension (Yan et al. 2003), and depressed subjects are more likely to develop hypertension (Meng et al. 2012).

Stress has drawn attention as a risk factor for cardiovascular diseases, and according to the results of INTERHEART study, stress is an independent risk factor for myocardial infarction (Rosengren et al. 2004). However, the role of psychological stress was inconclusive as various studies were coming to different results. Several stressors were studied with respect to their association with cardiovascular events, for example living circumstances, loss of job, occupational stress, and major life events.

There are two major research approaches in assessing the impact of stress on health. The first approach relies on the assessment of environmental factors or psychosocial experiences that are considered objectively stressful, such as major life events. The second approach focuses on subjective evaluations of stress experiences, in other words on self-reported stress. Conflicting results were obtained from trials using these two different methodological approaches in measuring stress. While most studies using objective measures showed positive associations with the development of hypertension, no associations and sometimes even inverse associations were found in studies using subjective measures (Nyklícek et al. 1996).

\subsection{Chronic stressors}

In studies using animal models, psychological stress combined with genetic background was found to be involved in the etiology of hypertension (Henry et al. 1993). A variety of chronic stressors have been assessed as potential risk factors for the development of hypertension, and more importantly, they were studied for their contributions to adverse cardiovascular outcome. One of the most studied stressors is job-related stress which has been shown to be an important risk factor for the development of hypertension (Schnall et al. 1998), and is associated with a higher frequency of cardiovascular diseases (Rozanski et al. 2005). 
Socio-economic status (SES) is defined generally as a combination of different factors such as educational level, occupational status, financial resources, and social status. Low socio-economic status is considered to be associated with a composite of chronic stressors, as people from lower socio-economic status are more likely to be exposed to stressful circumstances. Numerous trials have examined the association between SES and morbidity, and longitudinal studies indicate a strong and consistent gradient between SES level and different diseases, including adverse cardiac events and stroke (Pickering 1999; Rozanski et al. 2005) and carotid atherosclerosis (Lynch et al. 1995; Lynch et al. 1998). This gradient is inversed, meaning that people from lower social economic status are more susceptible to cardiovascular diseases than people in middle and higher socio-economic status. However, the gradient for hypertension and SES was weak and in some studies even absent.

A large body of evidence suggests that the level of social support is linked to both psychological and somatic health (Knox and Uvnäs-Moberg 1998; Uno et al. 2002; Bøen et al. 2012), and consistent literature shows that poorer social support is associated with worse mental and somatic health outcomes. It was reported that the lack of social support is associated with higher mortality after myocardial infarction (Frasure-Smith et al. 2000). The concept of social support can be divided into two broad spectrums: social networks and functional support. This includes on the one hand the quality and quantity of support provided by the social network and on the other hand the perceived social support. The latter focuses on the subjective appraisal of the provided support or the perception that support would be available if needed (Rozanski et al. 2005). Studies showed that people with higher functional social support have less atherosclerosis compared with those with poor social support (Seeman and Syme 1987).

Stressors related to social circumstances were also accused to be contributing to the morbidity of cardiovascular diseases. Caregiving strain was studied in detail and was reported to be associated with higher occurrence of cardiac events (Schulz and Beach 1999; Lee et al. 2003). Marital stress is another social factor which was reported to predict prognosis in women with coronary heart disease. The prognosis in women who had no partner was better than those with stressful marriages and worse than those with satisfying marriages (Orth-Gomer et al. 2000; Gallo et al. 2003). 


\subsection{Stress and stress systems}

\subsubsection{Background}

The homeostasis of the organism is constantly threatened by different external or internal stimuli which are called stressors and induce a wide range of possible reactions towards internal or external, psychological or physical factors. According to this hypothesis, stress can be defined as a process that actually or at least theoretically challenges homeostasis (Chrousos 2009).

The concept of stress is complex and defined in different ways. While some authors define it as a state of the mind that comprises both body and brain and the interactions between them (McEwen 1998), others define it as a situation that involves excessive environmental demands, with which the organism or the individual cannot readily adapt (Sparrenberger et al. 2009). It is conceivable that an imbalance in the stress system may promote pathological changes leading to cardiovascular diseases and/or mental disorders.

Acute stressful experiences include major life events and trauma, while chronic stress on the other hand describes the accumulation of daily minor stressors which could be related to the environment at home, workplace, or in the neighborhood. Both acute and chronic stress can have long-term medical consequences (McEwen 1998). The physiological responses to acute stressors are considered to be an adaptive process that aims to increase the survival of the organism against possible threats by maintaining the homeostasis. This complex process is mediated mainly by the hypothalamic-pituitary-adrenal (HPA) system, leading to different reactions (Chrousos 2009). When the stress is frequent or persistent these responses could become maladaptive and may cause potential harm to the organism and increase the risk for different diseases. This phenomenon is referred to as allostatic load and is defined as the exhaustion of the stress system caused by long-standing exposure to different stressors (McEwen 1998).

The interaction between the stress and the different reactions of the stress system is suggested to take an inverted U-shaped dose-response curve. The central range of the curve is considered to represent the optimal basal healthy homeostasis (or eustasis). The state of suboptimal effects happening on either side of the curve is called 
allostasis. Both extremes of the curve represent an insufficient adaptation status which might be harmful for the organism (Chrousos 2009).

Both hypoactivation and hyperactivation of the stress systems of the organism have on the short term and/or long term many adverse effects. Allostatic (adaptive) system boundaries are relatively broad, unlike homeostatic systems such as blood oxygen, blood $\mathrm{pH}$, which should remain within narrow ranges. Allostatic systems mediate the organism's responses to physical states (awake, asleep, changing position) and to adapt with different environmental circumstances such as noise, living in a crowded area, isolation, hunger, cold, heat, dangerous situations, and infection (microbial or parasitic).

The basic physiologic response of the body to a stressor consists of two phases. The first phase involves turning on an allostatic response which consists of complex adaptive reactions. This initial phase is called reactivity and includes changes in endocrinological, cardiovascular, immunological, and/or behavioral parameters. The second phase comprises shutting off this responses and returning to baseline when the threat is gone. This second phase is called recovery and is defined as the period of time during which the previously mentioned altered parameters go back to their baseline; in other words it gives information about the persistence of the reactivity (Linden et al. 1997).

As mentioned before, the complex allostatic responses involve the HPA axis in addition to the sympathetic nervous systems. During the reactivity phase, activation of these systems leads to release of catecholamines from the adrenal medulla and sympathetic nerves, which in turn mediates the secretion of corticotropin from the pituitary gland, and eventually causes the secretion of cortisol from the adrenal cortex.

During recovery, inactivation of the allostatic system occurs by setting cortisol and catecholamine secretion back to their baseline levels, which normally happens when the stressful situation is over. While the activation phase is important as it protects the organism against potential dangers, the inactivation of these systems is also of physiological significance, as its inefficiency leads to continuous overexposure to stress hormones. This overexposure in turn can cause allostatic load which is 
typically associated with many adverse consequences on the organism (McEwen 1998).

\subsubsection{Abnormal responses to stress}

Four scenarios are associated with allostatic load. The first scenario is exposure to frequent stress which leads to repeated activation of the stress system as a result of repeated exposure to different stressors. This can cause pathological consequences; for example, repeated elevations of blood pressure can on long term enhance atherosclerosis, with its known adverse complications. The second scenario of allostatic load is the lack of adaptation to repeated exposure to stressors of the same kind; this pattern implies that the organism will be exposed for a prolonged period to stress hormones. The third scenario of allostatic load is the prolonged response caused by the failure to turn off allostatic responses when the stressor is no longer present. The fourth scenario of allostatic load includes insufficient responses of some allostatic systems leading to an increase of the activity of other systems. This happens because the underactive system is no longer providing the required counterregulation (McEwen 1998).

\subsubsection{Cardiovascular system and reactions to stress}

Cardiovascular reactivity in particular includes changes in hemodynamic parameters, such as elevation in blood pressure and changes in heart rate and cardiac index, which are considered to be typical physiological reactions towards external stimuli. Using the cold pressor test as a paradigm for an acute laboratory stressor, a rise in blood pressure was frequently observed, and this cardiovascular reactivity was found to be higher in persons with diagnosed hypertension as well as persons with a family history of hypertension (Wood et al. 1984). These observations form the basis of the reactivity hypothesis which suggests that exaggerated cardiovascular reactivity can have a predictive value for the risk of future hypertension (Krantz and Manuck 1984). This hypothesis was supported by many longitudinal studies suggesting that greater cardiovascular reactivity may promote the development of hypertension (Matthews et al. 1993; Menkes et al. 1989; Matthews et al. 2004). 


\subsubsection{Hypertension-induced hypoalgesia}

The correlation between blood pressure levels and different aspects of mental wellbeing was frequently reported in some trials. The inverse relationship between blood pressure and sensitivity to pain was also a subject for research in the late seventies, including animal models of spontaneous hypertensive rats exposed to noxious stimuli (Dworkin et al. 1979; Friedman et al. 1984; Maixner et al. 1982).

These findings were reproduced in humans, as it was shown that hypertensive patients have less pain sensitivity compared with normotensive individuals. This association was also found in healthy subjects who have a positive family history of hypertension. Outside of experimental conditions, post-surgery pain is clearly inversely associated with blood pressure values. It was even suggested that decreased pain perception could be used as a predictor of later development of hypertension (Page and France 1997; France 1999).

Different mechanisms were reported to play a role in this process, including endogenous opioids and the baroreceptor reflex. The baroreceptors are stretch sensitive mechanoreceptors which are located in the carotid arteries and the aortic arch, transmitting information about the amplitude and change of blood pressure on a beat-to-beat basis. The arterial baroreflex is part of a homeostatic, control-loop mechanism that aims to keep blood pressure within a physiological range around a regulatory set-point. This is achieved through the autonomic nervous system which mediates negative feedback changes by adjusting heart rate, cardiac contractility, and vascular resistance (Rau and Elbert 2001). When blood pressure rises thereby extending the vessel walls, the baroreceptors increase their firing frequency, which is then transferred along vagal and glossopharyngeal nerves to the nucleus tractus solitarii (NTS) in the medulla oblongata. These afferent signals are then transfered to other nuclei of the central nervous system. As a consequence, heart rate, cardiac contractility, and vascular resistance are reduced decreasing arterial blood pressure toward the regulated set-point (Dampney 1994).

In animals, exposure to psychological stress evokes cortical and subcortical brain regions, and it is well established that this suppresses the baroreflex through a pathway affecting brainstem nuclei which are responsible for autonomic cardiovascular control (Dampney 1994). It was suggested that in humans similar cortical and subcortical regions are involved in processing psychological stressors 
and influence the autonomic nuclei leading to suppression of parasympathetic cardiac control and activation of sympathetic vascular outflow. As a result of baroreceptor reflex suppression, blood pressure rises above the regulated set-point, and both heart rate and blood pressure rise together. Such cardiovascular reactions may be exaggerated and possibly pathogenic in some individuals (Gianaros et al. 2012) 


\section{Methods and materials}

\subsection{DEGS1 study}

\subsubsection{Background and aims}

The German Health Interview and Examination Survey for Adults (DEGS) is a large survey representative of the German population which was funded by the German Federal Health Ministry and carried out by the Robert Koch Institute (RKI). It is a part of a health monitoring program and aims to obtain nation-wide health data that reflect the health status of adults who lived in Germany at the time of the study. In addition to collecting cross-sectional data, it was also planned to collect longitudinal data by repeating the examination and interview of the same individuals. This longitudinal design enables analyzing changes over time in different domains of health issues in this representative sample.

The first wave of data collection (DEGS1) was conducted between November 2008 and December 2011, and it consisted of an examination and interview survey, which aimed to collect comprehensive data and detailed information about health status, health behaviors, living conditions, and using the health care services. The study sample was divided into two age groups, those aged 18-64 years and those aged 65 years and older, with different protocols being used for each group (Scheidt-Nave et al. 2012).

The interview part comprises computer-assisted personal interviews (CAPI) and selfcompleted questionnaires. Physician-administered interview included also questions that address a wide spectrum of health issues. Previous illnesses, vaccinations, previous operations, diagnostic procedures as well as current and previous medications were all covered by the interview.

Participants were asked in details about their medications using the computerassisted assessment of medication. Any medications or dietary supplements were reported if participants have taken them within the last 7 days. For each drug or product, detailed information were obtained about the indication, the dosage, the frequency and duration of use, and whether the medication was obtained on prescription or over the counter. 
Participants were also provided with self-completed questionnaires, in order to get a good idea about their health status, regarding different physical, psychological and social aspects. Some of these questionnaires were administered exclusively to participants aged between 18-64 years, such as TICS-SSCS.

Blood samples and anthropometric measurements were always performed at the beginning of the interview. Participants were asked to fast before their appointment, and most of them had agreed to. Participants were then given a healthy snack of fresh bread, fruit, and decaffeinated drinks. For each participant, anthropometric measurements including body height and weight as well as blood pressure, pulse and thyroid volume measurements were recorded. In addition, venous blood samples and urine samples were obtained for laboratory analyses. For participants younger than 65 years, bicycle ergometer test was included in the examination, and for the older group physical and cognitive capabilities were tested (Gößwald et al. 2013).

\subsubsection{Study participants}

The present post-hoc study of the DEGS survey included participants who were aged between 18-64 years and whose values of self-perceived chronic stress as assessed with TICS-SSCS were available. A total of 958 individuals were excluded because they were currently taking antihypertensive medications (beta-blockers, calcium channel blockers, angiotensin-converting-enzyme inhibitors, and other bloodpressure lowering drugs) as classified according to the WHO Anatomical Therapeutic Chemical (ATC) classification system (Knopf and Grams 2013; Neuhauser et al. 2013), and another 17 participants were also excluded because no valid data about their use of antihypertensive medication were available. Since the analyses are performed in participants who were working at the time of the survey, 808 individuals who were not currently employed were excluded. The final study population hence comprised a total of 3,352 adults (1711 women, 1641 men).

\subsubsection{Sampling design and weighting factors}

The target population of the DEGS1 included adults between 18-79 years of age, who reported Germany to be their main residence place and were living in Germany 
during the survey time. This sampling included not only subjects from the German population but also persons belonging to other nationalities (Kamtsiuris et al. 2013).

The sampling procedure consisted of two stages, which were the selection of sampling points and the selection of target persons. The total number of sampling points was 180 , of them 120 were the sampling points from a former national survey, namely the German National Health Interview and Examination Survey 1998 (GNHIES98). To these retained sampling points 60 newly selected points were added to ensure that the actual German population is presented. In the next step, men and women of the target age group were selected randomly from the population registries of the sample points.

For subjects of non-German nationality, the participation rate was expected to be less than others. For this reason, an oversampling factor of 1.5 was used to overcome the expected higher non-responsiveness and non-eligibility rates. The response rate in DEGS1 is considered average, as $62 \%$ of the GNHIES98 participants who were invited to re-participate have responded, while only $42 \%$ of the newly invited persons have responded (Kamtsiuris et al. 2013).

Sample weights were calculated in order to allow for deriving representative conclusions about the adult population in Germany in cross-sectional analysis and also to perform longitudinal analysis. Cross-sectional sample weights were calculated for both the newly invited group and the re-invited group and then these weights were combined together for the total sample. Finally, sample weights were adjusted according to the population in Germany to compensate for the study design-related clustering and stratification and also for non-response.

\subsection{Blood Pressure measurement}

After five minutes of rest, three consecutive standardized measurements of blood pressure and heart rate were performed with three minute intervals in between. The automatic blood pressure monitor Datascope Accutorr Plus (Datascope Corporation Mahwah, NJ, USA) was used for this purpose, which is the same apparatus used in the German Health Interview and Examination Survey for Children and Adolescents (KIGGs) study. This monitor uses an oscillometric method, and it is compatible with the gold standard of the auscultatory measurement using standard mercury sphygm- 
omanometry according to the criteria of the Association for Advancement of Medical Instrumentation and the British Hypertension society (O'Brien et al. 2001; White et al. 2003). In both the oscillometric and auscultatory method, pressure cuffs should be inflated to exceed the level of the expected systolic blood pressure. The auscultatory method depends on gradual release of pressure in the cuff and detecting Korotkoff sounds using a stethoscope on the brachial artery. The first and last of these sound are considered to represent systolic and diastolic blood pressure, respectively. This procedure requires well-trained examiners who can identify these sounds correctly. In contrast, the oscillometric method depends on the automatic analysis of the oscillations of the vascular wall which are transferred to the pressure cuff, and the values of both systolic and diastolic blood pressure are determined according to the assessment of these oscillations.

All blood pressure measurements were performed following a standardized protocol in which the examined participant sat in upright position, while legs were not crossed and feet were set on the floor, with the right forearm resting on a table at the level of the heart. Three different sizes of inflatable cuffs were used corresponding to the circumference of the participant's upper right arm. The sizes were as following: a small cuff (cuff bladder $10.5 \times 23.9 \mathrm{~cm}$ ) which was used when the circumference of the upper arm was ranging from 21 to $27.9 \mathrm{~cm}$, a medium cuff (cuff bladder $13.5 \times 30.7$ $\mathrm{cm}$ ) when the circumference of the upper arm was in the range of $28-35.9 \mathrm{~cm}$, and for an upper arm circumference within the range of $36-46 \mathrm{~cm}$, a large cuff (cuff bladder $17 \times 38.6 \mathrm{~cm}$ ) was used. The upper arm circumference was determined by identifying the acromion (highest point of the shoulder blade) and the olecranon (the tip of the elbow), and then measurements were performed at the level of half distance between the above-mentioned two anatomical points. During the measurements, no talking took place, and the participant was not informed about any findings till the end of the process (Neuhauser et al. 2013).

To ensure that these measurements were performed following the standardized examination protocol, regular quality control was performed. The values of systolic and diastolic blood pressure were defined as the mean of the second and third automatic recordings.

Participants were asked if they have had ever a diagnosis of hypertension or elevated blood pressure as confirmed by a physician. They were also asked whether 
they were taking any medications for the purpose of lowering blood pressure. The interview included all medications taken over the previous week. Coding drugs was in accordance with the World Health Organization's (WHO) Anatomic Therapeutic Chemical Classification System (ATC code). The following medications were reported as being antihypertensives: diuretics (ATC code: C03), beta-blockers (C07), calcium channel blockers (C08), ACE inhibitors (C09) and other antihypertensive drugs (C02) (Knopf and Grams 2013).

\subsection{Chronic stress assessment}

Chronic stress among participants in DEGS1 was measured using the screening scale of the Trier Inventory for the assessment of chronic stress (TICS-SSCS). This standardized scale measures self-perceived stress during the last 3 months, and it comprises twelve items to investigate how often the participants perceive their life as being stressful. It covers five different aspects of stress, which are chronic worry, excessive requirements, work-related stress, social overload, and lack of social recognition. The answers to the questions were rated according to stress frequency from 0 to 4 , where 0 point stands for "never", 1 point for "rarely", 2 points for "sometimes", 3 points for "often", and 4 points for "very often". The total score was defined as the sum of the individual items scores, allowing answers to be missing for no more than three items. Accordingly, this score can vary between 0 and 48 points, so that a score of 0 points means reporting no stress in all of the above-mentioned stress domains, and a score of 48 points means that stress is perceived as highly frequent in all five stress domains covered by the questionnaire. The values of the total TICS-SSCS scores were available for 5,802 participants. Based on the publication of Hapke and colleagues (2013), the following categories of stress were determined, depending on the distribution of the total score values: $0-11$ points ( $\leq$ median) "below-average to average stress", 12-22 points "above-average stress", and $23-48$ points ( $\geq 90$ th percentile) "extreme stress". Participants older than 65 years of age were not included (Hapke et al. 2013). 


\subsection{Job-related stress assessment}

The index used for measuring job-related stress in the DEGS1 study was recently developed by Kroll and colleagues (2011). This index was designed specifically for German samples, and it used data from a large representative study including approximately 20,000 employees in Germany (Kroll 2011; Santi et al. 2013). This instrument assessing occupational burden is in accordance with data that used the International Standard Classification of Occupations edition 1988 (ISCO-88) by the International Labour Organization. In total, five domains of occupational burden were covered in this index including Ergonomic Stress, Environmental Pollution, Mental Stress, Social Stress, and Temporal Loads. The first two domains form together the Physical Job Index (PJI), while the later three domains were used to construct the Psycho-Social Index (PSI). The sum of all the subscales was used to form the Overall Job Index (OJI). Data from the German Health Update 2009 and the German SocioEconomic Panel Study were used for the external validation of these indices. The values of the indices range between 1 and 10, indicating the deciles of jobs in ascending order according to their occupational burdens. Index group 10 includes jobs associated with particularly heavy occupational load, such as miners and machinery workers, while index group 1 includes jobs that have the lowest occupational burden, such as teachers and bookkeepers (Santi et al. 2013).

\subsection{Definition of covariables}

Socio-economic status (SES) of the participants in DEGS was defined using an index which was derived from data about education level, occupation and net household income. According to this index participants were classified into low, medium or high SES (Lampert et al. 2013b).

The Oslo 3 Support Scale was used to determine self-perceived social support. This international questionnaire contains three different questions: a first question about the number of confidants, and a second question about the perceived interest of other people, and a third question regarding the relationship with neighbors (Dalgard et al. 2006). The total score is produced by summing the individual item scores ranging between 3 and 14. Based on this score, three different categories can be formed: poor support (3-8), moderate support (9-11), and strong support (12-14) (Hapke et al. 2013). 
To assess current depressive symptoms in participants of the DEGS1 study, the depression module of the German version of the Patient Health Questionnaire-9 (PHQ-9) was used. The PHQ-9 is a well-validated, self-administered and commonly used instrument for assessing the severity of depression (Kroenke et al. 2001). It includes nine questions that measure both the presence and frequency of depressive symptoms within the last two weeks. The 9 items of the PHQ-9 consist of the actual nine criteria on which the diagnosis of DSM-IV depressive disorders is based. Because of this, PHQ-9 can serve two purposes at the same time with the same nine items; it can establish not only a diagnosis of depressive disorder but it also measures the severity of depressive symptoms. For each question, scores were assigned depending on the frequency of symptoms ranging from 0 to 3 , where 0 means "not at all", and 3 means "nearly every day" for each item. The total score is calculated by summing individual item scores, which ranged from 0 and 27 , with a total score of 10 or more usually indicating current depressive symptoms (Busch et al. 2013).

Alcohol consumption was reported using the AUDIT-C (Alcohol Use Disorders Identification Test-Consumption) scale (Hapke et al. 2013). For smoking behavior, classification of the participants was as following: daily smokers, occasional smokers, previous smokers, and non-smokers (Lampert et al. 2013a). Regarding physical activity, a five-grade scale was used asking the participants about the number of sport hours practiced per week (Krug et al. 2013). For reporting familial stand participants were categorized according to whether they were living with a partner (married or cohabitating) or not, and for caregiving they were asked whether they were taking care of an ill relevant or not.

\subsection{Statistical analysis}

To present the characteristics of the study sample, means and standard errors for continuous variables, as well as percentages and standard errors for categorical variables were calculated. Systolic blood pressure was used as the dependent variable in a set of general linear models (GLMs), with either TICS-SSCS score or each one of job indices (OJI, PJI and PSI) as independent variables. In the next step, the same models were initially adjusted for age, sex, and BMl (body-mass-index). Another GLM was then computed for TICS-SSCS score with the above-mentioned 
covariates in addition to the following covariates: alcohol consumption, smoking behavior, sport activity, traffic intensity, living without a partner, social support, caregiving, Socio-economic status and the Overall Job Index. The same set of models was computed using diastolic blood pressure as the dependent variable.

To test for possible effects of stress on the pattern of blood pressure change across the three consecutive measurements, repeated measure general linear models were computed in which systolic or diastolic blood pressure was entered as the dependent variable and self-reported stress categories were entered as between-subject variables. All analyses were conducted with a weighting factor which corrected deviations in the sample from the German population regarding age, sex, region, nationality, community type, and education (Kamtsiuris et al. 2013). In all tests, a pvalue $<0.05$ was used to indicate statistical significance.

Due to the clustered design of the DEGS1 sampling, all statistical analyses were performed using the Complex Samples procedure in the software package SPSS-22 (except for repeated measure general linear models, as such model is not available in complex sample software package). The complex sampling design has many advantages, as it limits costs and time that would be associated with random sampling to get representative statements on the public level, and it addresses issues of non-response rate and insures representing minorities adequately (Kneipp and Yarandi 2002). However, analyzing data derived from such samples can be challenging as it cannot be performed using software packages designed for simple random samples, as complex samples cannot meet the assumptions of simple random sampling. A simple random sample requires that all subjects in the population can be assessed, and therefore having equal probability of being selected, independently of choosing of other subjects. On the other hand when complex sampling designs are used, the probabilities of inclusion are not equal. Thus, each participant (or subjects) should be given weights to compensate for this inequality of selection probabilities.

Several reports showed that analyzing data collected for a complex sampling design using conventional statistical software packages (originally designed for samples that meet random sampling assumptions) is associated with smaller standard errors, which causes smaller confidence intervals and leads to a higher probability that a true null hypothesis is rejected (type-I error). Using weighting factors for analyzing 
these data helps for adjusting for over- and under-sampling of groups in the population. The calculated estimates for groups consider their original proportion in the population, regardless of the proportion in the sample. However it was emphasized that using weighting alone is not enough without using software packages designed for complex samples, because complex sample data analysis should take into consideration not only weights but also clustering, and stratification of the sampling design to produce representative estimates of population means and frequencies from the study cohort (Saylor et al. 2012). 


\section{Results}

\subsection{Characterization of the study cohort}

The mean age in the study group was $39.3 \pm 0.2$ years. Among the study population, there were $47.7 \%$ women, while men constituted $52.3 \pm 1.2 \%$. The mean body-massindex was $25.7 \pm 0.1 \mathrm{~kg} / \mathrm{m}^{2}$. The mean value of systolic blood pressure was $121.9 \pm$ $0.3 \mathrm{mmHg}$, and the mean diastolic blood pressure was $72.9 \pm 0.2 \mathrm{mmHg}$. In the study population, the mean TICS-SSCS score was $12.0 \pm 0.18$. Table 1 shows the characteristics of the study group as calculated using the complex sample procedure.

The mean value of Overall Job Index was $5.3 \pm 0.1$. Table 2 shows the distribution of the participants across the job indices deciles.

\begin{tabular}{|c|c|}
\hline Variable & $\begin{array}{c}\text { Study sample } \\
\quad(n=3352)\end{array}$ \\
\hline \multicolumn{2}{|c|}{ Continuous variables (mean \pm SE) } \\
\hline Age (years) & $39.3 \pm 0.2$ \\
\hline Body-mass-index $\left(\mathrm{kg} / \mathrm{m}^{2}\right)$ & $5.7 \pm 0.1$ \\
\hline Screening Scale of Chronic Stress & $12.0 \pm 0.18$ \\
\hline Overall Job Index & $5.28 \pm 0.08$ \\
\hline Physical Job Index & $5.36 \pm 0.08$ \\
\hline Psycho-social Job Index & $5.30 \pm 0.06$ \\
\hline PHQ-9 & $4.06 \pm 0.08$ \\
\hline Alcohol consumption (AUDIT-C) & $3.4 \pm 0.05$ \\
\hline Systolic blood pressure $(\mathrm{mmHg})$ & $121.9 \pm 0.3$ \\
\hline Diastolic blood pressure $(\mathrm{mmHg})$ & $72.9 \pm 0.2$ \\
\hline \multicolumn{2}{|c|}{ Categorical variables (percentage $\pm S E$ ) } \\
\hline Sex (men) & $52.3 \pm 1.2$ \\
\hline \multicolumn{2}{|l|}{ Socio-economic status } \\
\hline Low & $13.7 \pm 0.9$ \\
\hline Middle & $62.0 \pm 1.2$ \\
\hline
\end{tabular}




\begin{tabular}{|l|c|}
\hline High & $24.3 \pm 1.2$ \\
\hline Social support & \\
Poor & $9.1 \pm 0.6$ \\
Moderate & $49.7 \pm 1.1$ \\
Strong & $41.2 \pm 1.2$ \\
\hline Smoking & \\
Daily smokers & $28.4 \pm 1.0$ \\
Occasional smokers & $7.5 \pm 0.6$ \\
Ex-smokers & $25.0 \pm 0.9$ \\
Non-smokers & $39.1 \pm 1.0$ \\
\hline Sport activity & \\
No sport activity & $28.6 \pm 1.1$ \\
Less than 1 hour per week & $17.6 \pm 0.8$ \\
Regularly 1-2 hours per week & $26.2 \pm 0.9$ \\
Regularly 2-4 hours per week & $16.4 \pm 0.8$ \\
Regularly more than 4 hours per week & $11.2 \pm 0.7$ \\
\hline Living in partnership & \\
Yes & $81.0 \pm 0.8$ \\
No & $19.0 \pm 0.8$ \\
\hline Caregiving & \\
Yes & \\
No & $91.3 \pm 1.1$ \\
\hline Traffic intensity & $9.7 .7 \pm 0.5$ \\
Very little traffic & \\
Moderate traffic & \\
Considerable traffic & \\
Heavy traffic & \\
Extreme traffic & \\
\hline
\end{tabular}

Table 1: Characteristics of participants whose TICS-SSCS scores were available and who were employed at the time of survey, and were not taking antihypertensive medications. 


\begin{tabular}{|c|c|c|c|}
\hline & \multicolumn{3}{|c|}{ Percentage \pm SE of job indices } \\
\hline $\begin{array}{c}\text { Job } \\
\text { category }\end{array}$ & $\begin{array}{c}\text { Overall Job Index } \\
\text { (OJI) }\end{array}$ & $\begin{array}{c}\text { Physical Job Index } \\
\text { (PJI) }\end{array}$ & $\begin{array}{c}\text { Psycho-social Job } \\
\text { Index (PSI) }\end{array}$ \\
\hline 1 & $12.0 \pm 0.7$ & $9.4 \pm 0.7$ & $9.8 \pm 0.7$ \\
\hline 2 & $10.2 \pm 0.6$ & $11.4 \pm 0.7$ & $11.9 \pm 0.6$ \\
\hline 3 & $9.1 \pm 0.7$ & $10.0 \pm 0.7$ & $10.7 \pm 0.7$ \\
\hline 4 & $11.8 \pm 0.7$ & $10.4 \pm 0.6$ & $11.3 \pm 0.7$ \\
\hline 5 & $8.6 \pm 0.6$ & $10.5 \pm 0.7$ & $9.2 \pm 0.6$ \\
\hline 6 & $10.6 \pm 0.7$ & $10.0 \pm 0.7$ & $10.5 \pm 0.7$ \\
\hline 7 & $11.2 \pm 0.8$ & $12.5 \pm 0.8$ & $9.3 \pm 0.7$ \\
\hline 8 & $9.9 \pm 0.7$ & $8.1 \pm 0.7$ & $9.0 \pm 0.6$ \\
\hline 9 & $8.8 \pm 0.8$ & $10.2 \pm 0.8$ & $9.6 \pm 0.7$ \\
\hline 10 & $7.8 \pm 0.6$ & $7.6 \pm 0.7$ & $8.6 \pm 0.6$ \\
\hline
\end{tabular}

Table 2: Distribution of study sample in the ten job categories according to the three job indices.

The present analyses are focused on the relationship between blood pressure on one hand and different measures of stress and other factors, with systolic or diastolic blood pressure being used as the dependent variables in the models. Both systolic and diastolic blood pressure were normally distributed as shown in Figure 1, meaning that they can be used without transformation. 


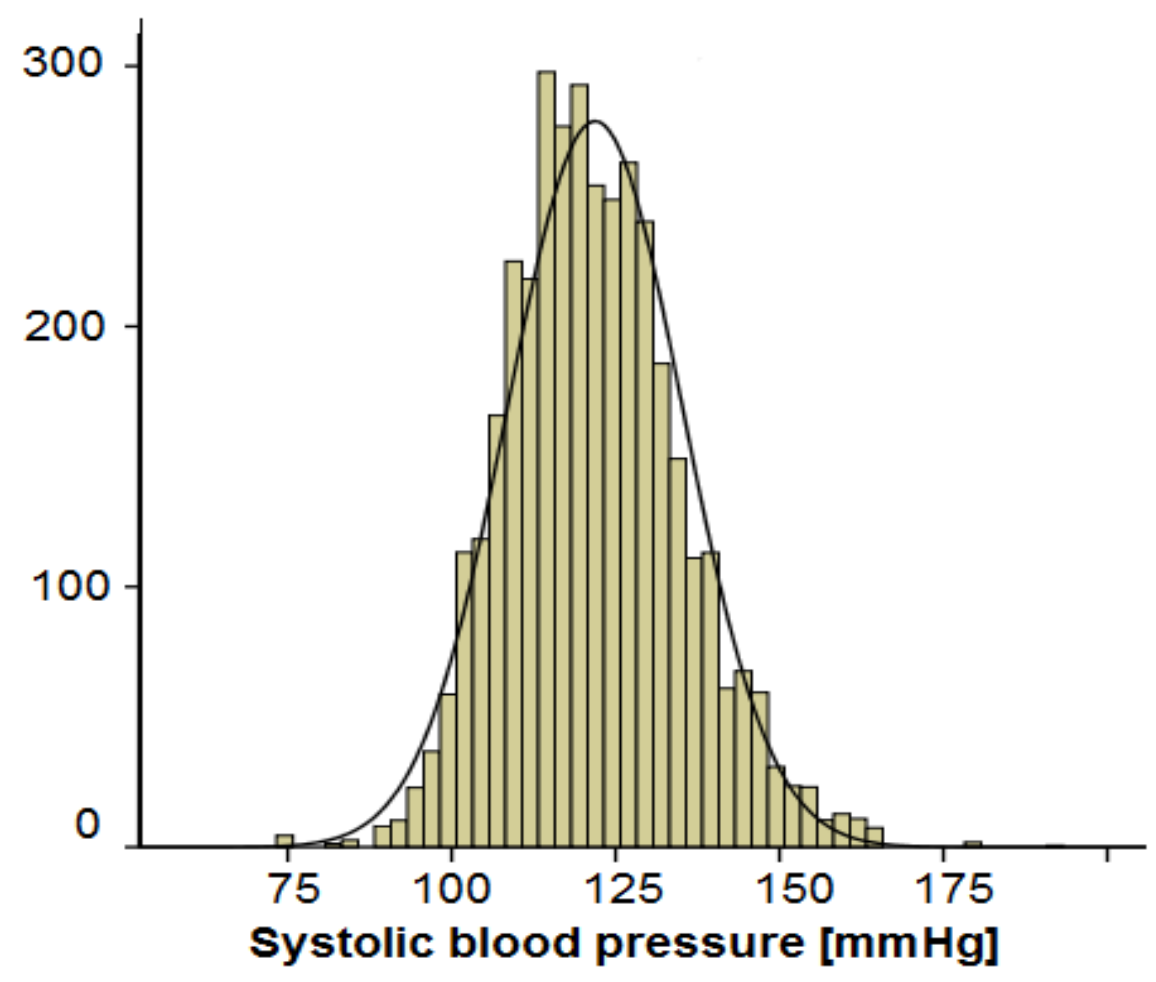

A

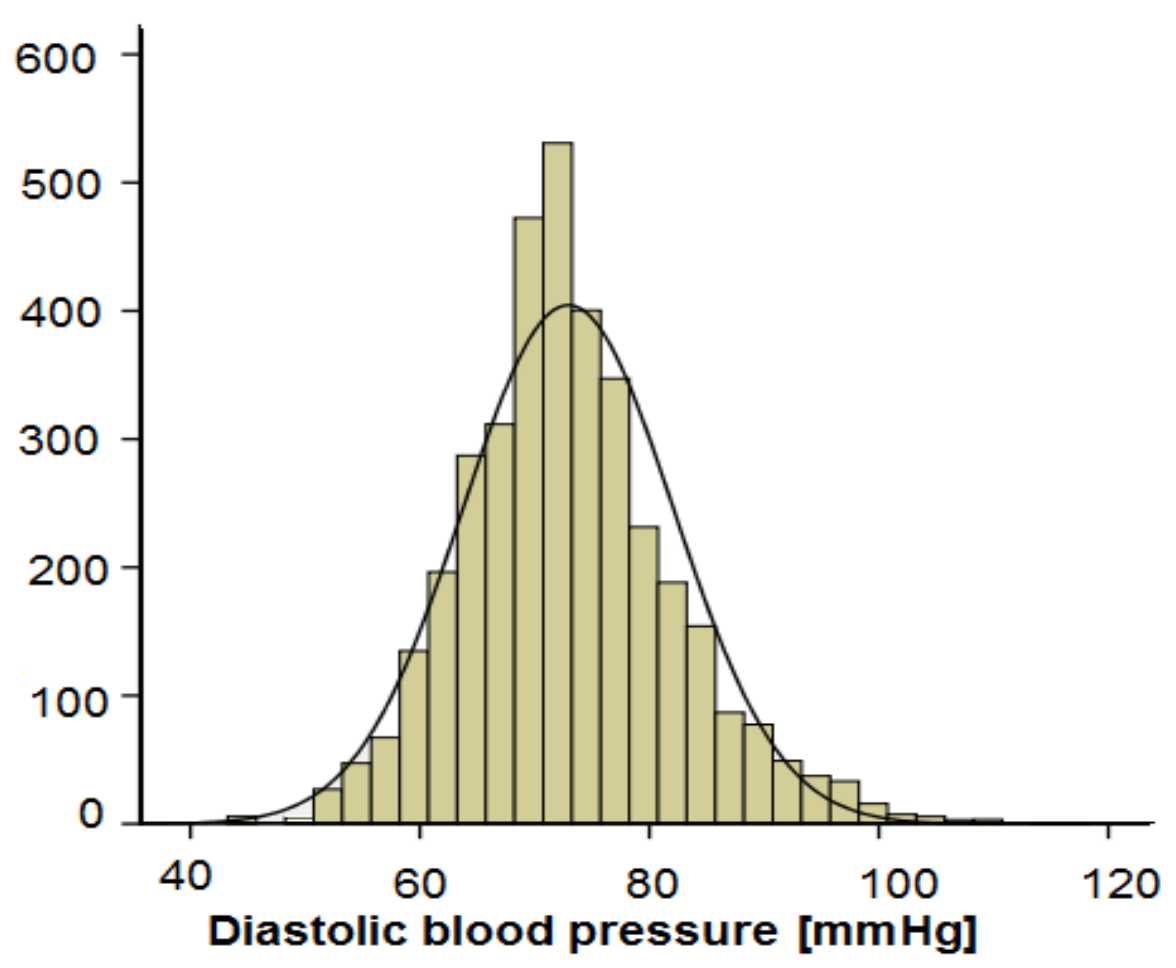

B

Figure 1: Histograms showing the normal distribution of systolic $(A)$ and diastolic blood pressure $(B)$ values in the study cohort. 


\subsection{Bivariate analyses}

As a first step in investigating the possible association between blood pressure and stress, either systolic or diastolic blood pressure was entered as the dependent variable, while measures of self-reported stress as determined by TICS-SSCS and job indices were included as independent variables.

The results demonstrated that self-reported stress as measured by TICS-SSCS was significantly and negatively associated with systolic blood pressure (Table 3). On the other hand, the Overall Job Index (OJI) showed a positive and significant association with systolic blood pressure (Table 3). The Physical Job Index also showed a positive association with systolic blood pressure (Table 3). However, the Psycho-social Index showed no significant association with systolic blood pressure.

\begin{tabular}{|l|c|c|c|c|}
\hline $\begin{array}{c}\text { Dependent variable: } \\
\text { Systolic blood pressure }\end{array}$ & Estimate & SE & Confidence interval & p-value \\
\hline Chronic stress (TICS-SSCS) & -0.160 & 0.034 & $-0.228-(-0.092)$ & $<0.001$ \\
\hline Overall Job Index (OJI) & 0.438 & 0.112 & $0.216-0.659$ & $<0.001$ \\
\hline Physical Job Index (PJI) & 0.489 & 0.114 & $0.264-0.715$ & $<0.001$ \\
\hline Psycho-social Index & 0.163 & 0.110 & $-0.054-0.381$ & 0.140 \\
\hline
\end{tabular}

Table 3: Bivariate associations between systolic blood pressure and measures of stress showing significant negative association with TICS-SSCS and positive associations with OJI and PJI.

Similar results were found when diastolic blood pressure was entered as the dependent variable. Again, self-reported stress as measured by TICS-SSCS showed negative and significant association with diastolic blood pressure (Table 4), indicating that higher diastolic blood pressure was linked to less perceived stress. Similarly, the Overall Job Index and the Physical Job Index showed a positive association with diastolic blood pressure (Table 4). Similar to systolic blood pressure, the Psycho- 
social Index showed no significant association with diastolic blood pressure in bivariate analysis.

\begin{tabular}{|l|c|c|c|c|}
\hline \multicolumn{1}{|c|}{$\begin{array}{c}\text { Dependent variable: } \\
\text { Diastolic blood pressure }\end{array}$} & Estimate & SE & Confidence interval & $p$-value \\
\hline Chronic stress (TICS-SSCS) & -0.102 & 0.024 & $-0.149-(-0.055)$ & $<0.001$ \\
\hline Overall Job Index (OJI) & 0.204 & 0.071 & $0.063-0.344$ & 0.005 \\
\hline Physical Job Index (PJI) & 0.241 & 0.075 & $0.09-0.388$ & 0.002 \\
\hline Psycho-social Index & 0.054 & 0.068 & $-0.080-0.188$ & 0.425 \\
\hline
\end{tabular}

Table 4: Bivariate associations between diastolic blood pressure and measured stress parameters, demonstrating significant positive associations with OJI and PJI, no significant association with PSI, and significant negative association with TICSSSCS.

In order to illustrate the association between blood pressure values and self-reported stress estimated by TICS-SSCS graphically, scatter plots were computed and the linearity was tested. The results from these calculations showed that $R$ square was low ( $R^{2}=0.009$ for systolic blood pressure, and $R^{2}=0.007$ for diastolic blood pressure), implying the existence of a very low linearity. However, this linear relationship was significant ( $p<0.001$ for both systolic and diastolic blood pressure) ( Figure 2). 


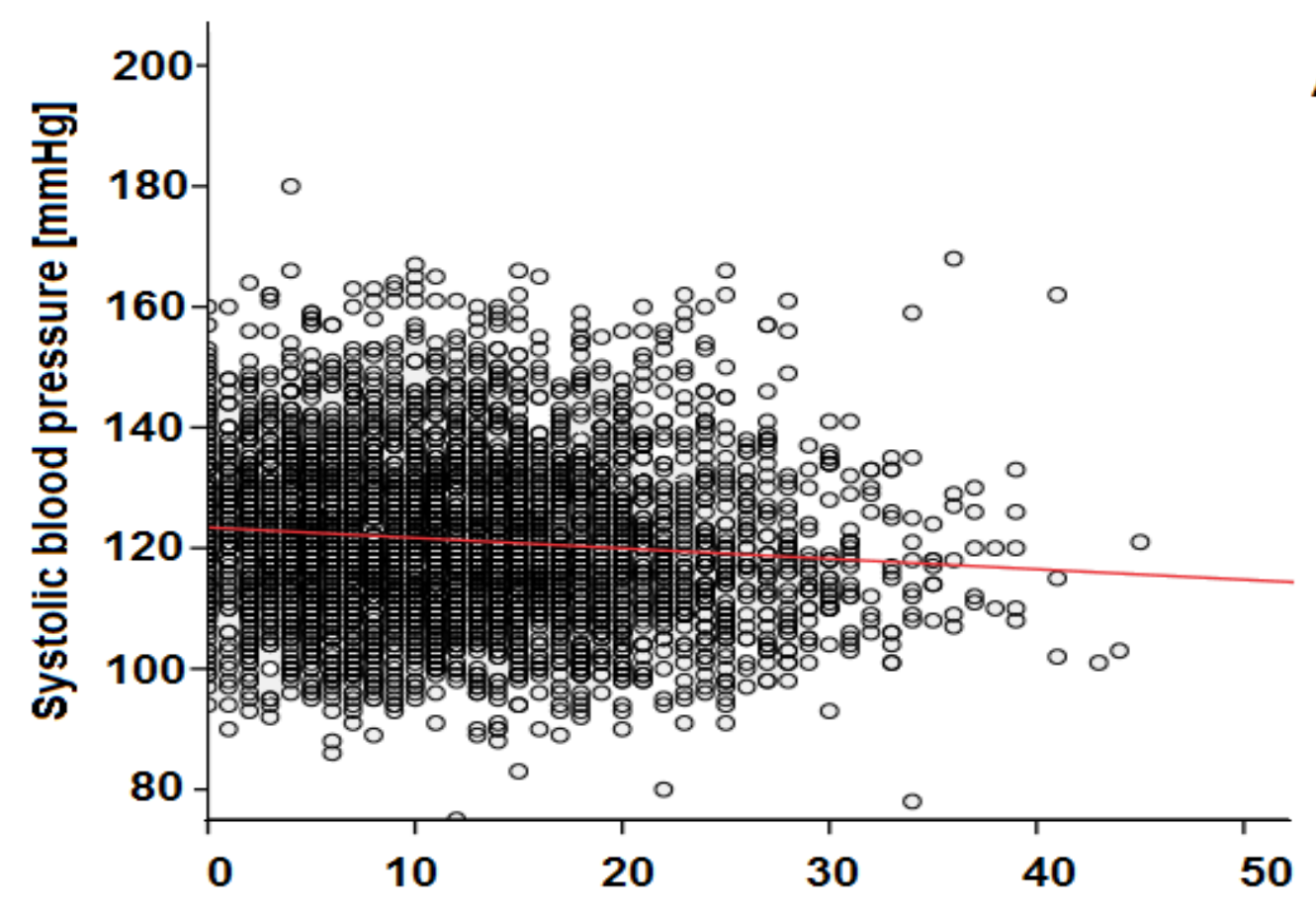

TICS Screening scale of chronic stress score

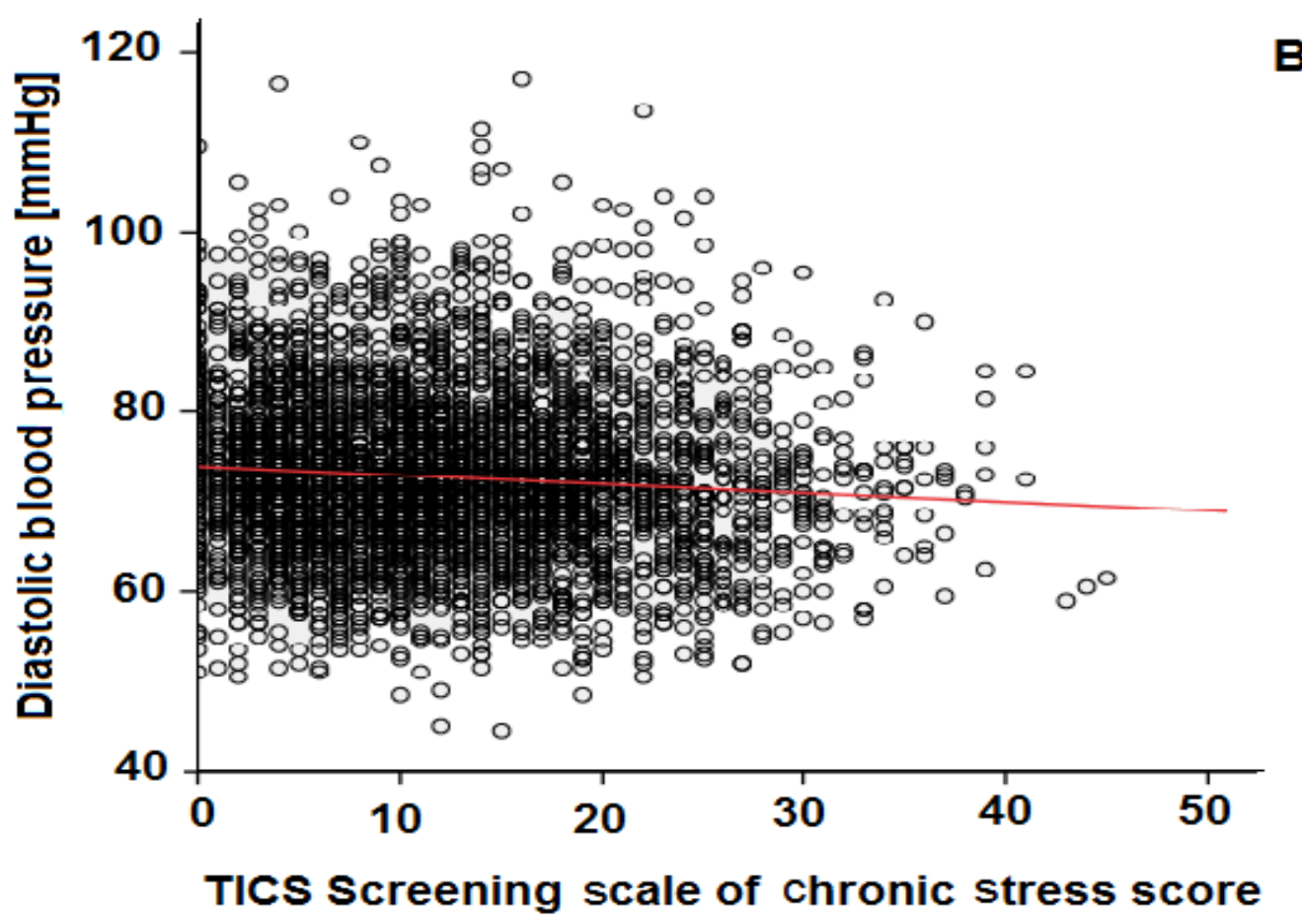

Figure 2: Scatter blot diagrams showing the inverse association between systolic $(A)$ and diastolic (B) blood pressure and TICS-SSCS. 
Next, I studied the associations between systolic or diastolic blood pressure on one hand and a variety of potential confounders on the other hand by entering them in separate models as independent variables (Table 5). Significant associations were observed for systolic blood pressure with smoking habits and alcohol consumption, and for diastolic blood pressure with socio-economic status, smoking habits, sport activity, living in partnership and alcohol consumption.

\begin{tabular}{|c|c|c|c|c|c|c|}
\hline & \multicolumn{3}{|c|}{$\begin{array}{l}\text { Dependent variable: } \\
\text { Systolic blood pressure }\end{array}$} & \multicolumn{3}{|c|}{$\begin{array}{l}\text { Dependent variable: } \\
\text { Diastolic blood pressure }\end{array}$} \\
\hline & Estimate & SE & $\mathrm{p}$-value & Estimate & SE & $\mathrm{p}$-value \\
\hline SES (referent: high SES) & & & 0.450 & & & 0.014 \\
\hline Low & -1.047 & 1.012 & & -1.888 & 0.697 & \\
\hline Middle & 0.053 & 0.636 & & -0774 & 0.430 & \\
\hline $\begin{array}{l}\text { Social support (referent: } \\
\text { strong social support) }\end{array}$ & & & 0.422 & & & 0.352 \\
\hline Poor & 0.876 & 0.965 & & 0.317 & 0.729 & \\
\hline Moderate & 0.689 & 0.530 & & 0.551 & 0.367 & \\
\hline $\begin{array}{l}\text { Smoking habits (referent: } \\
\text { Non-smokers) }\end{array}$ & & & $<0.001$ & & & $<0.001$ \\
\hline Daily smoker & 0.412 & 0.684 & & -0.307 & 0.481 & \\
\hline Occasional smokers & -2.029 & 1.177 & & -1.624 & 0.745 & \\
\hline Ex-Smokers & 3.156 & 0.622 & & 2.414 & 0.424 & \\
\hline $\begin{array}{l}\text { Sport activity (referent: } \\
\text { regularly }>4 \text { h per week) }\end{array}$ & & & 0.082 & & & $<0.001$ \\
\hline
\end{tabular}




\begin{tabular}{|l|c|c|c|c|c|c|}
\hline No sport activity & 0.908 & 1.076 & & 2.875 & 0.740 & \\
Less than 1h per week & -0.732 & 1.033 & & 1.064 & 0.725 & \\
Regularly 1-2h per week & -1.319 & 1.098 & & 1.070 & 0.712 & \\
Regularly 2-4h per week & -1.125 & 1.083 & & 0.896 & 0.763 & \\
\hline Traffic intensity (referent: & & & 0.509 & & & 0.698 \\
Extreme traffic ) & & & & & & \\
Very little traffic & 0.803 & 1.171 & & 0.682 & 0.946 & \\
Moderate traffic & 1.126 & 1.130 & & 0.870 & 0.966 & \\
Considerable traffic & 2.296 & 1.444 & & 1.216 & 1.061 & \\
Heavy traffic & 0.541 & 1.399 & & 0.304 & 1.027 & \\
\hline Living in partnership & & & & & & \\
(referent: Living without a \\
partner)
\end{tabular}

Table 5: Bivariate associations between systolic or diastolic blood pressure and different confounders. Some confounders, such as smoking habits and alcohol consumption, showed significant associations for both systolic and diastolic blood pressure, while socio-economic status, sport activity and living in partnership were associated significantly only with diastolic blood pressure.

\subsection{Multivariate analyses}

In the next set of general linear models, age, sex and body-mass-index were added to the measures of stress, which showed in bivariate analyses significant association with blood pressure values. Self-reported stress as measured by TICS-SSCS remained significantly associated with systolic blood pressure (Table 6). However, in these multivariate analyses the Overall Job Index lost its significant association with systolic blood pressure (Table 7). The Physical Job Index also lost the significant 
association with systolic blood pressure when the model was adjusted for the abovementioned parameters (Table 8). Similar results were obtained when this set of models using diastolic blood pressure as the dependent variable were adjusted for age, sex and body-mass-index. The inverse association between diastolic blood pressure and TICS-SSCS remained significant, when these confounders were additionally included in the model (Table 6). However, as shown before for systolic blood pressure, both the Overall Job Index and the Physical Job Index lost their positive significance (Tables 7,8$)$.

\begin{tabular}{|l|c|c|c|c|c|c|}
\hline & \multicolumn{3}{|c|}{ Dependent variable: } & \multicolumn{2}{c|}{$\begin{array}{c}\text { Dependent variable: } \\
\text { Systolic blood pressure } \\
\text { Diastolic blood pressure }\end{array}$} \\
& \multicolumn{2}{|c|}{ (Total model $\left.R^{2}=0.210\right)$} & \multicolumn{2}{c|}{ (Total model $\left.R^{2}=0.218\right)$} \\
\hline & Estimate & SE & p-value & Estimate & SE & $p$-value \\
\hline Age (per year) & 0.161 & 0.021 & $<0.001$ & 0.237 & 0.015 & $<0.001$ \\
\hline Sex (referent: women) & 8.759 & 0.529 & $<0.001$ & 4.104 & 0.377 & $<0.001$ \\
\hline BMI (per unit) & 0.607 & 0.070 & $<0.001$ & 0.363 & 0.043 & $<0.001$ \\
\hline $\begin{array}{l}\text { Perceived chronic stress } \\
\text { (TICS-SSCS) } \\
\text { (per score unit) }\end{array}$ & -0.068 & 0.031 & 0.029 & -0.056 & 0.022 & 0.010 \\
\hline
\end{tabular}

Table 6: General linear models using systolic or diastolic blood pressure as the dependent variable and age, sex, body-mass-index (BMI), and TICS-SSCS as independent variables. In these models, TICS-SSCS showed negative and significant associations with the two dependent variables. 


\begin{tabular}{|l|c|c|c|c|c|c|}
\hline & \multicolumn{3}{|c|}{$\begin{array}{c}\text { Dependent variable: } \\
\text { Systolic blood pressure } \\
\left.\text { (Total model } R^{2}=0.212\right)\end{array}$} & \multicolumn{2}{c|}{$\begin{array}{r}\text { Dependent variable: } \\
\text { Diastolic blood pressure } \\
\left.\text { (Total model } R^{2}=0.211\right)\end{array}$} \\
\hline & Estimate & SE & p-value & Estimate & SE & $p$-value \\
\hline Age (per year) & 0.172 & 0.022 & $<0.001$ & 0.237 & 0.016 & $<0.001$ \\
\hline Sex (referent: women) & 8.907 & 0.532 & $<0.001$ & 4.370 & 0.374 & $<0.001$ \\
\hline BMI (per unit) & 0.608 & 0.070 & $<0.001$ & 0.358 & 0.044 & $<0.001$ \\
\hline $\begin{array}{l}\text { Overall Job Index } \\
\text { (per decile) }\end{array}$ & 0.10 & 0.103 & 0.922 & -0.023 & 0.067 & 0.737 \\
\hline
\end{tabular}

Table 7: General linear models using systolic or diastolic blood pressure as the dependent variable adjusted for age, sex, BMI, and OJI. No significant associations were found between the Overall Job Index (OJI) and either systolic or diastolic blood pressure.

\begin{tabular}{|l|c|c|c|c|c|c|}
\hline & \multicolumn{3}{|c|}{$\begin{array}{c}\text { Dependent variable: } \\
\text { Systolic blood pressure } \\
\end{array}$} & \multicolumn{2}{c|}{$\begin{array}{c}\text { Dependent variable: } \\
\text { Diastolic blood pressure } \\
\end{array}$} & \multicolumn{2}{|c|}{ (Total model $\left.R^{2}=0.212\right)$} & \multicolumn{2}{c|}{ (Total model $\left.R^{2}=0.211\right)$} \\
\hline & Estimate & SE & p-value & Estimate & SE & p-value \\
\hline Age (per year) & 0.172 & 0.022 & $<0.001$ & 0.237 & 0.016 & $<0.001$ \\
\hline Sex (referent: women) & 8.853 & 0.530 & $<0.001$ & 4.33 & 0.373 & $<0.001$ \\
\hline BMI (per unit) & 0.604 & 0.070 & $<0.001$ & 0.354 & 0.044 & $<0.001$ \\
\hline $\begin{array}{l}\text { Physical Job Index } \\
\text { (per decile) }\end{array}$ & 0.073 & 0.104 & 0.485 & 0.023 & 0.070 & 0.749 \\
\hline
\end{tabular}


Table 8: Results from two general linear models using systolic or diastolic blood pressure as the dependent variables adjusted for the indicated variables. Neither systolic nor diastolic blood pressure showed significant association with the Physical Job Index.

As both TICS-SSCS and job indices are independent measures of stress, bivariate analyses were performed to test the correlation between them. Unexpectedly, neither the Overall Job Index nor its two components were significantly associated with TICS-SSCS (for the Overall Job Index $p=0.204$, for the Physical Job Index $p=0.136$, and for the Psycho-Social Index $\mathrm{p}=0.522$ ).

Additional potential confounders were entered to newly computed general linear models using systolic blood pressure as dependent variable. These models included traffic intensity, living in partnership, caregiving, and socio-economic status, as those factors can be considered as stressors, as well as social support that could have a positive effect. Additional confounders were considered such as behavioral variables that could affect the level of blood pressure and interact with stress such as alcohol consumption, smoking, and physical activity. The Overall Job Index was also entered into the same model with TICS-SSCS to investigate their interaction. The results demonstrated that TICS-SSCS once again remained significantly related to systolic blood pressure (Estimate=-0.09, $\mathrm{SE}=0.03, \mathrm{p}=0.007$ ) (Table 9). Likewise, when the above-mentioned confounders were additionally added into a model using diastolic blood pressure as dependent variable, TICS-SSCS again remained a significant predictor (Estimate=-0.08, SE=0.02, $\mathrm{p}=0.001$ ) (Table 9). 


\begin{tabular}{|c|c|c|c|c|c|c|}
\hline & \multicolumn{3}{|c|}{$\begin{array}{l}\text { Dependent variable: } \\
\text { Systolic blood pressure } \\
\text { (Total model } \mathrm{R}^{2}=0.228 \text { ) }\end{array}$} & \multicolumn{3}{|c|}{$\begin{array}{l}\text { Dependent variable: } \\
\text { Diastolic blood pressure } \\
\text { (Total model } \mathrm{R}^{2}=0.233 \text { ) }\end{array}$} \\
\hline & Estimate & SE & $p$-value & Estimate & SE & $p$-value \\
\hline Age (per year) & 0.180 & 0.025 & $<0.001$ & 0.228 & 0.018 & $<0.001$ \\
\hline BMI (per unit) & 0.561 & 0.071 & $<0.001$ & 0.327 & 0.043 & $<0.001$ \\
\hline $\begin{array}{l}\text { Alcohol consumption } \\
\text { (per Audit C-score unit) }\end{array}$ & 0.468 & 0.136 & 0.001 & 0.092 & 0.094 & 0.331 \\
\hline $\begin{array}{l}\text { Perceived chronic stress } \\
\text { (TICS-SSCS) } \\
\text { (per score unit) }\end{array}$ & -0.091 & 0.034 & 0.007 & -0.075 & 0.023 & 0.001 \\
\hline $\begin{array}{l}\text { Overall Job Index } \\
\text { (per score unit) }\end{array}$ & 0.035 & 0.107 & 0.747 & 0.028 & 0.066 & 0.671 \\
\hline Sex (referent: women) & 8.170 & 0.642 & $<0.001$ & 4.196 & 0.431 & $<0.001$ \\
\hline $\begin{array}{l}\text { SES (referent: high SES) } \\
\text { Low } \\
\text { Middle }\end{array}$ & $\begin{array}{l}-0.520 \\
0.342\end{array}$ & $\begin{array}{l}1.012 \\
0.636\end{array}$ & 0.552 & $\begin{array}{l}-1.310 \\
-0.358\end{array}$ & $\begin{array}{l}0.697 \\
0.430\end{array}$ & 0.166 \\
\hline $\begin{array}{l}\text { Social support (referent: } \\
\text { strong social support) } \\
\text { Poor } \\
\text { Moderate }\end{array}$ & $\begin{array}{l}0.395 \\
0.350\end{array}$ & $\begin{array}{l}0.965 \\
0.530\end{array}$ & 0.783 & $\begin{array}{l}-0.223 \\
0.417\end{array}$ & $\begin{array}{l}0.729 \\
0.367\end{array}$ & 0.445 \\
\hline $\begin{array}{l}\text { Smoking habits (referent: } \\
\text { Non-smokers) } \\
\text { Daily smoker } \\
\text { Occasional smokers }\end{array}$ & $\begin{array}{l}-0.932 \\
-2.910\end{array}$ & $\begin{array}{l}0.684 \\
1.177\end{array}$ & 0.062 & $\begin{array}{l}-0.798 \\
-1.162\end{array}$ & $\begin{array}{l}0.481 \\
0.745\end{array}$ & 0.086 \\
\hline
\end{tabular}




\begin{tabular}{|c|c|c|c|c|c|c|}
\hline Ex-Smokers & 0.237 & 0.622 & & 0.328 & 0.424 & \\
\hline $\begin{array}{l}\text { Sport activity (referent: } \\
\text { regularly >4h per week) }\end{array}$ & & & \multirow[t]{5}{*}{0.194} & & & \multirow[t]{5}{*}{0.007} \\
\hline No sport activity & 1.297 & 1.076 & & 2.342 & 0.740 & \\
\hline Less than $1 \mathrm{~h}$ per week & 0.638 & 1.033 & & 1.295 & 0.725 & \\
\hline Regularly $1-2 \mathrm{~h}$ per week & -0.206 & 1.098 & & 0.855 & 0.712 & \\
\hline Regularly $2-4 \mathrm{~h}$ per week & -0.733 & 1.083 & & 0.256 & 0.763 & \\
\hline Traffic intensity (referent: & & & \multirow[t]{6}{*}{0.258} & & & \multirow[t]{6}{*}{0.825} \\
\hline Extreme traffic ) & & & & & & \\
\hline Very little traffic & 0.597 & 1.210 & & 0.462 & 0.903 & \\
\hline Moderate traffic & 0.641 & 1.197 & & 0.557 & 0.917 & \\
\hline Considerable traffic & 2.531 & 1.445 & & 0.865 & 0.973 & \\
\hline Heavy traffic & 1.292 & 1.305 & & 0.819 & 0.915 & \\
\hline $\begin{array}{l}\text { Living with a partner } \\
\text { (referent: No) }\end{array}$ & -0.981 & 0.703 & 0.165 & -0.033 & 0.489 & 0.946 \\
\hline Caregiving (referent: No) & -0.824 & 1.009 & 0.415 & 0.339 & 0.725 & 0.640 \\
\hline
\end{tabular}

Table 9: Results from two general linear models using systolic or diastolic blood pressure as the dependent variable and TICS-SSCS and OJI as dependent variables, adjusted for age, sex, BMI, smoking habits, sport activity, alcohol consumption, living in partnership, caregiving strain, SES, OSLO3 and traffic intensity. TICS-SSCS scores remained significantly associated with both systolic and diastolic blood pressure.

According to the literature, lower blood pressure is linked to higher frequency of depression (Hildrum et al. 2007), and higher self-reported stress is also associated with higher frequency of depressive symptoms (Hapke et al. 2013). Results from the present sub-analysis of the DEGS1 study showed that the bivariate association between PHQ-9 and TICS-SSCS was significant (Estimate $=0.273, \mathrm{SE}=0.010$, $\mathrm{p}<0.001)$. To confirm the observed association between self-perceived stress and blood pressure, the PHQ-9 sum-score was added as a covariable to the above- 
mentioned final models. The association between systolic or diastolic blood pressure and self-perceived chronic stress persisted, when PHQ-9 sum score of current depressive symptoms was additionally included in the final multivariable analyses (Estimate $=-0.091, \mathrm{SE}=0.041, \mathrm{p}=0.028$ for systolic blood pressure, and Estimate=$0.084, \mathrm{SE}=0.026, p=0.002$ for diastolic blood pressure).

\subsection{TICS-SSCS categories and individual items}

To explore the observed link between TICS-SSCS and blood pressure values in more details, the study cohort was divided into three subgroups according to the TICS-SSCS score (Hapke et al. 2013). The first group included participants with below-average TICS-SSCS scores (below median 11), the second group with aboveaverage scores (between 11 and 22), and the third group with extreme stress scores (more than 22).

To compare the three groups, ANOVA was applied using systolic blood pressure as the dependent variable. The mean values of systolic blood pressure significantly differed between the three stress categories $(p=0.001)$, and the below-average group had the highest mean blood pressure value, while the extreme stress group had the lowest value (Figure 3A). ANOVA was also performed using diastolic blood pressure as the dependent variable. As shown for systolic blood pressure, the mean values of diastolic blood pressure were also significantly different between the three stress groups $(p<0.001)$. Again, higher values of diastolic blood pressure belonged to the below-average stress group, while lower values of blood pressure belonged to the extreme stress group (Figure 3B). 

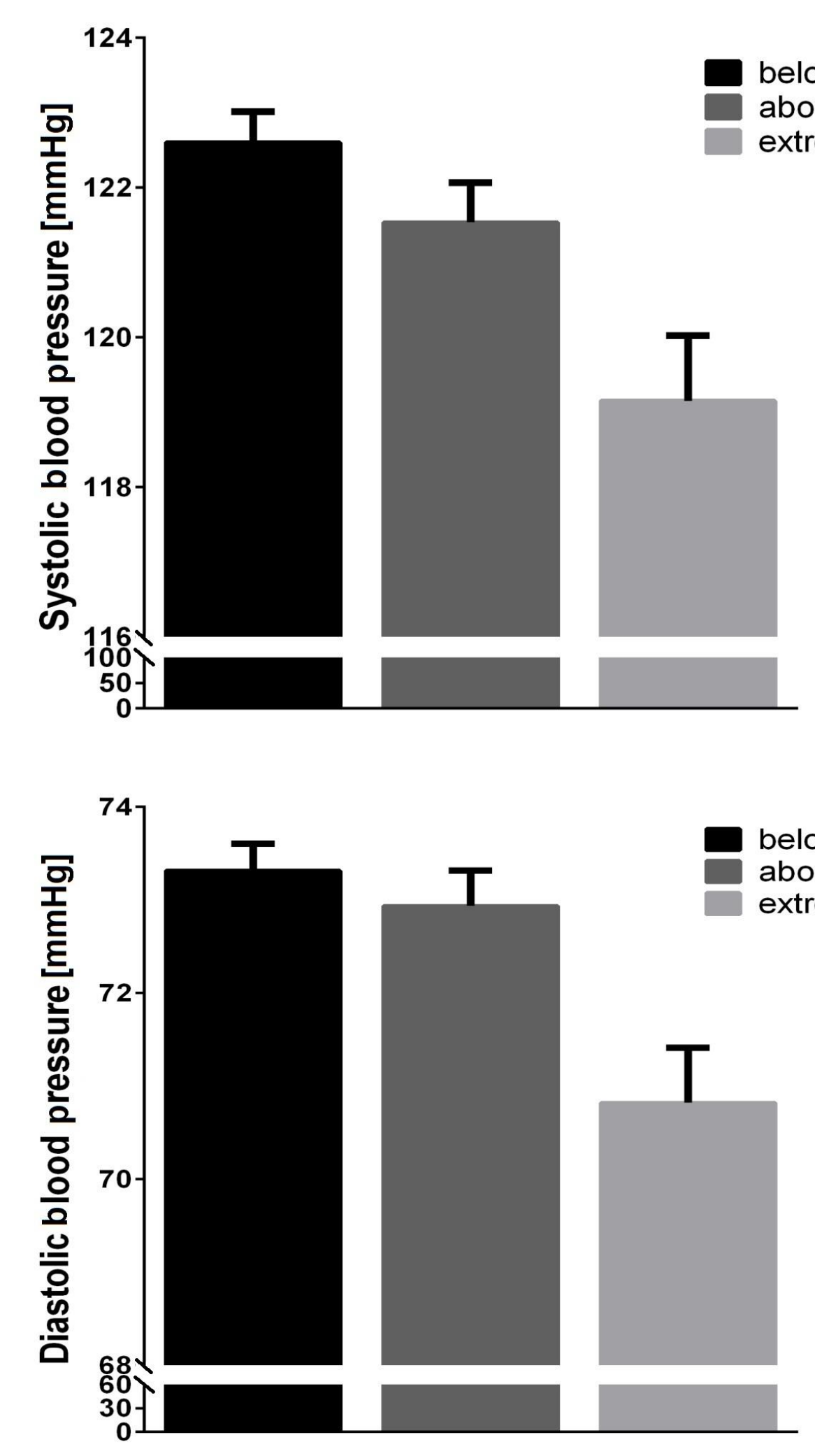

B

Figure 3: A comparison of systolic (A) and diastolic (B) blood pressure in the study participants who scored in the range of below-average (black columns), aboveaverage (dark gray columns) and extreme stress (light gray columns). Histograms depict the mean and standard error for each stress group. 
Bivariate analyses between TICS-SSCS and either systolic or diastolic blood pressure were calculated within each stress category. In the below-average stress group, the inverse association remained significant after using Bonferroni correction, in which the significance level was defined as 0.05 / 3 (the number of categories), while in the two upper stress groups the significance was lost (Table 10).

Next, ANOVAs were calculated for the association between blood pressure and each individual item of the stress scale (Figure 4). Most of the items (10 out of 12) showed a negative and significant association, indicating that participants reporting less frequent stress had higher blood pressure values, while those reporting very frequent stress showed lower blood pressure. Only item 5 showed a different direction for both systolic and diastolic blood pressure, and, notably, this question concerned appreciation at work (Table 11). The questions of the TICS-SSCS questionnaire provided in the DEGS study are shown in Appendix.

\begin{tabular}{|l|c|c|c|c|c|c|}
\hline & \multicolumn{3}{|c|}{$\begin{array}{c}\text { Dependent variable: } \\
\text { Systolic blood pressure }\end{array}$} & \multicolumn{2}{c|}{$\begin{array}{c}\text { Dependent variable: } \\
\text { Diastolic blood pressure }\end{array}$} \\
\hline & Estimate & SE & p-value & Estimate & SE & p-value \\
\hline Below-average stress & -0.338 & 0.103 & 0.001 & -0.201 & 0.078 & 0.011 \\
\hline Above-average stress & -0.068 & 0.213 & 0.751 & -0.049 & 0.127 & 0.702 \\
\hline Extreme stress & -0.252 & 0.208 & 0.226 & -0.209 & 0.134 & 0.121 \\
\hline
\end{tabular}

Table 10: Bivariate analyses using systolic or diastolic blood pressure as the dependent variable and TICS-SSCS score as the independent variable for each stress group. Results showed a significant negative association only in the belowaverage group. 


\begin{tabular}{|c|c|c|}
\hline & $\begin{array}{l}\text { Dependent variable: } \\
\text { Systolic blood } \\
\text { pressure }\end{array}$ & $\begin{array}{c}\text { Dependent variable: } \\
\text { Diastolic blood } \\
\text { pressure }\end{array}$ \\
\hline $\begin{array}{c}\text { Individual items of } \\
\text { Perceived chronic stress } \\
\text { (TICS-SSCS) }\end{array}$ & $\mathrm{p}$-value & $p$-value \\
\hline Item 1 & $<0.001$ & 0.001 \\
\hline Item 2 & $<0.001$ & 0.003 \\
\hline Item 3 & 0.358 & 0.091 \\
\hline Item 4 & $<0.001$ & 0.001 \\
\hline Item 5 & $<0.001$ & 0.003 \\
\hline Item 6 & 0.013 & 0.003 \\
\hline Item 7 & $<0.001$ & $<0.001$ \\
\hline Item 8 & 0.013 & 0.008 \\
\hline Item 9 & 0.028 & 0.005 \\
\hline Item 10 & $<0.001$ & $<0.001$ \\
\hline Item 11 & $<0.001$ & 0.001 \\
\hline Item 12 & 0.003 & 0.021 \\
\hline
\end{tabular}

Table 11: ANOVA models using systolic or diastolic blood pressure as the dependent variable and the five possible answers for each item of the TICS-SSCS as independent variable. 
Item 1

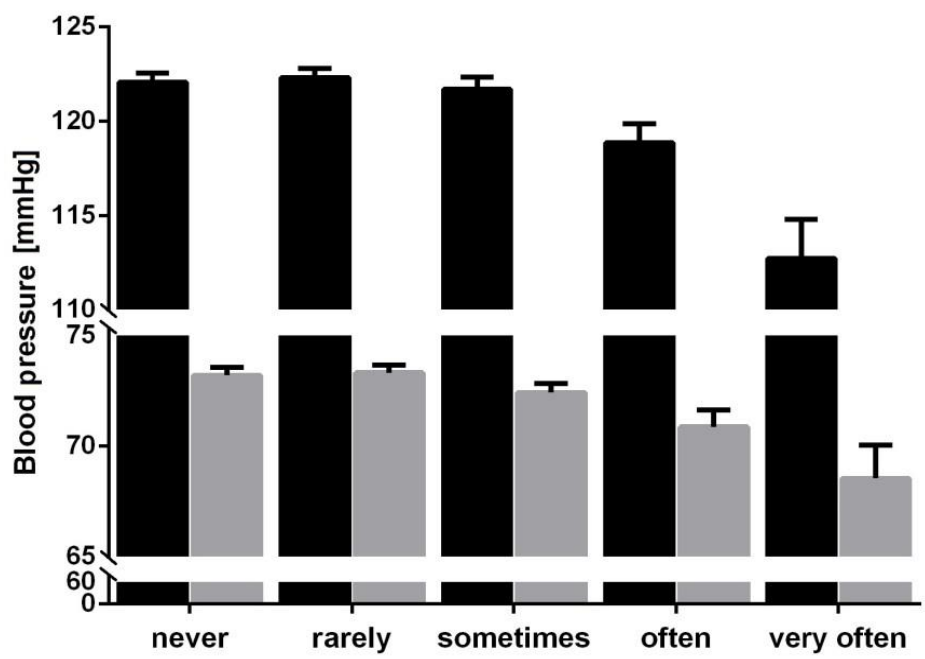

Item 3

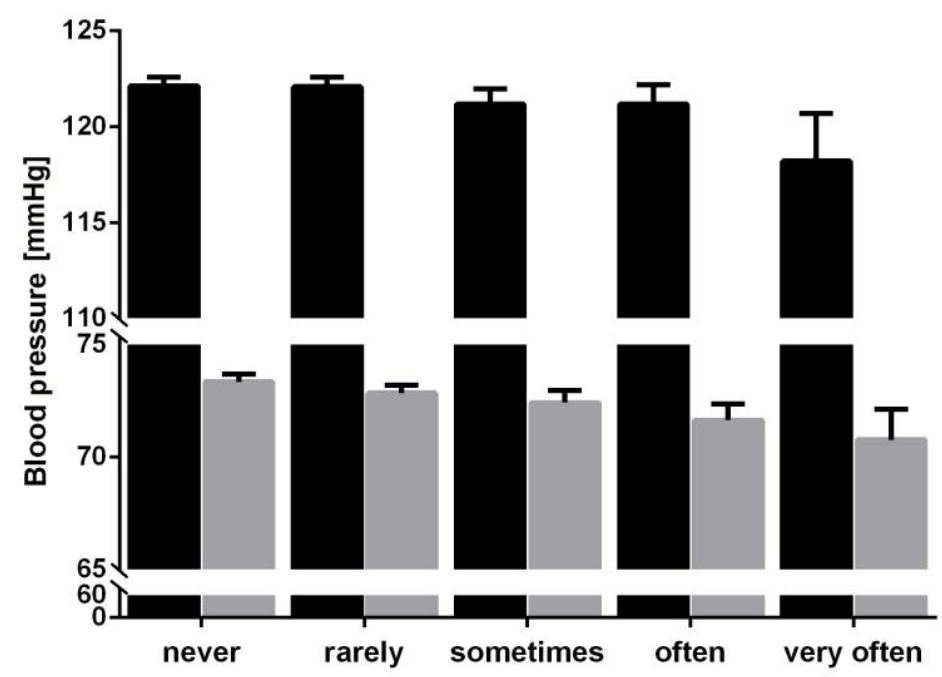

Item 5

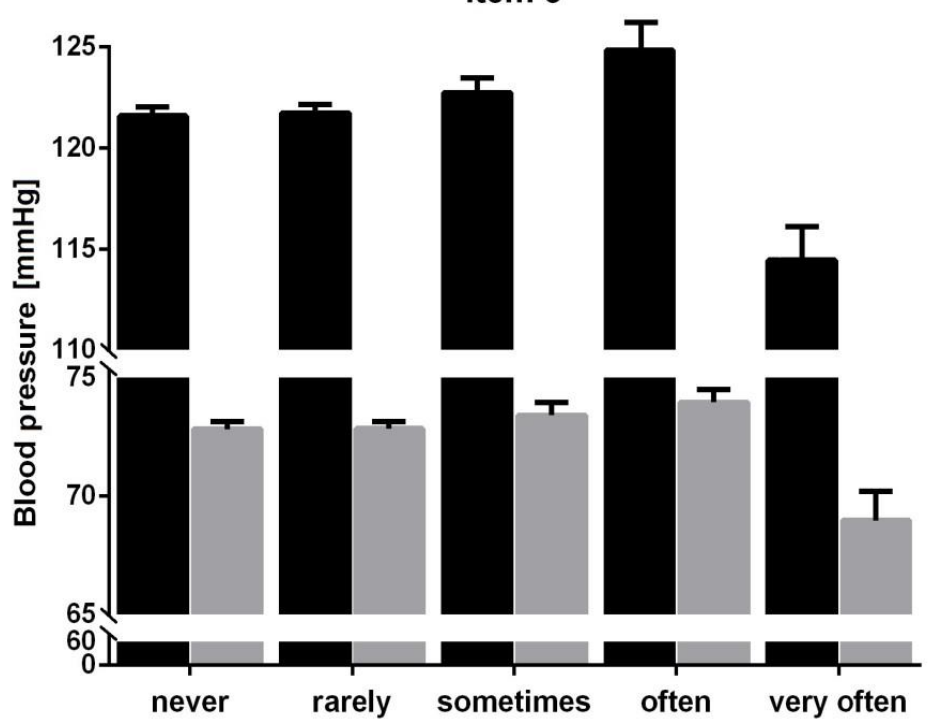

Item 2

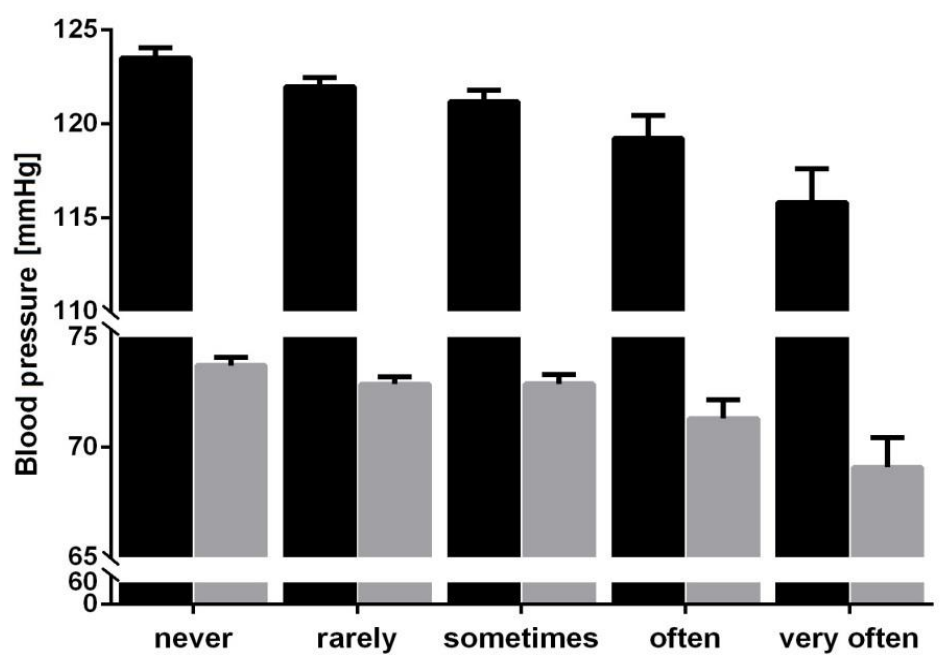

Item 4

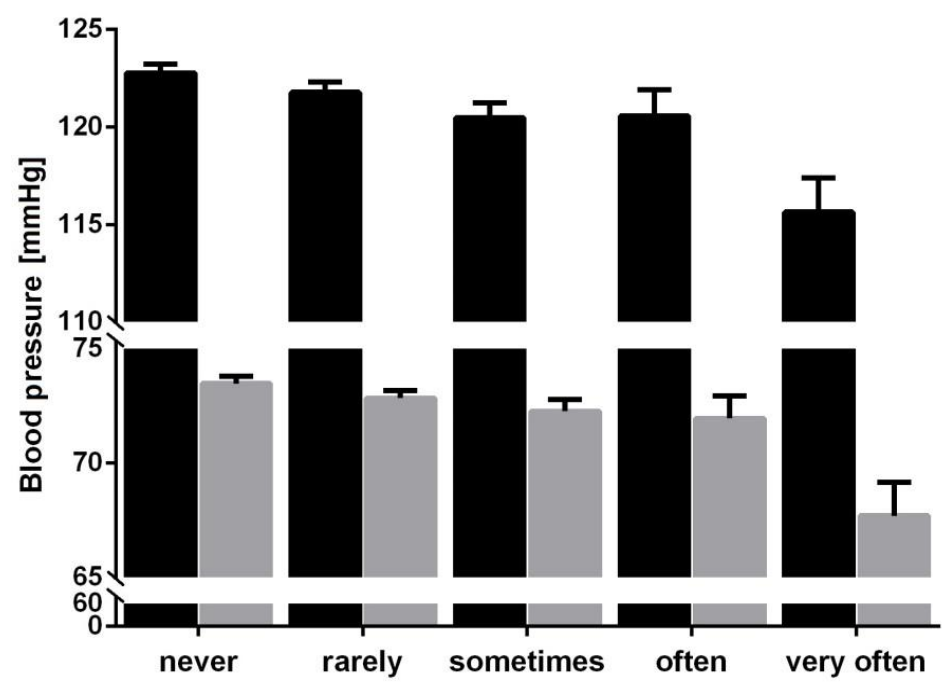

Item 6

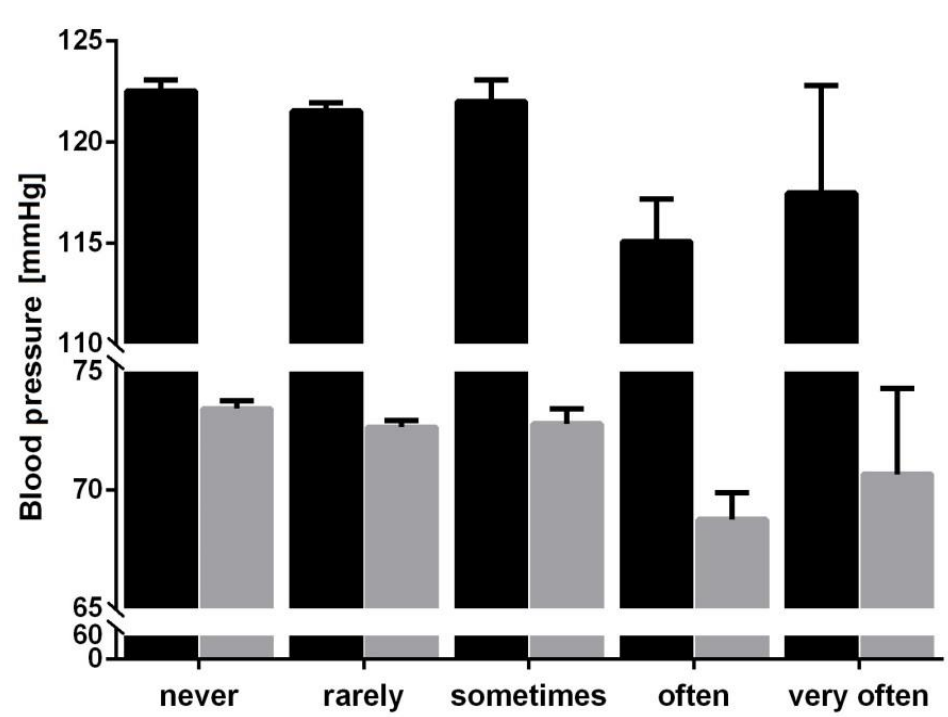


Item 7

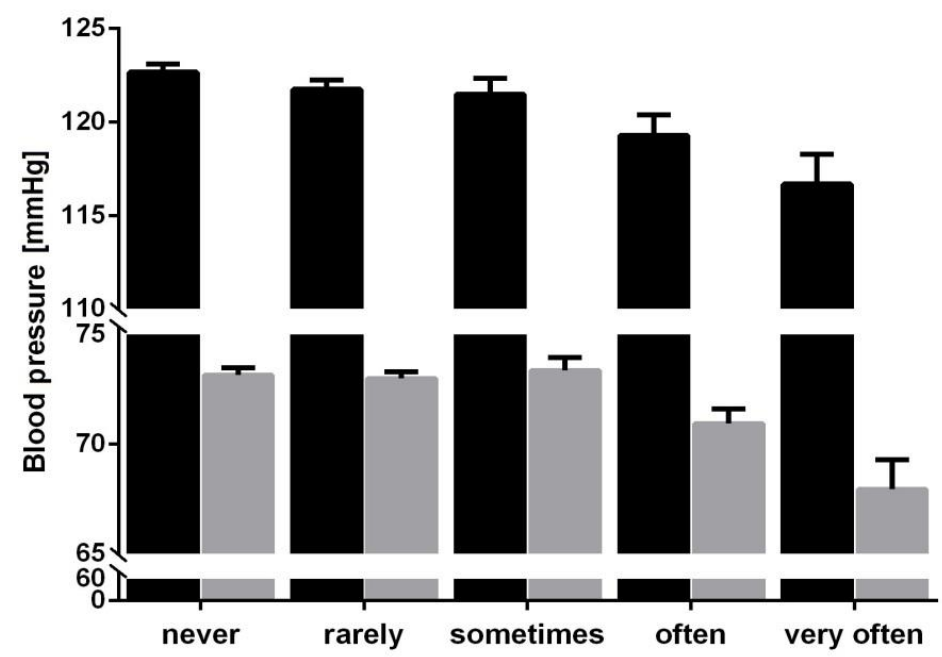

Item 9

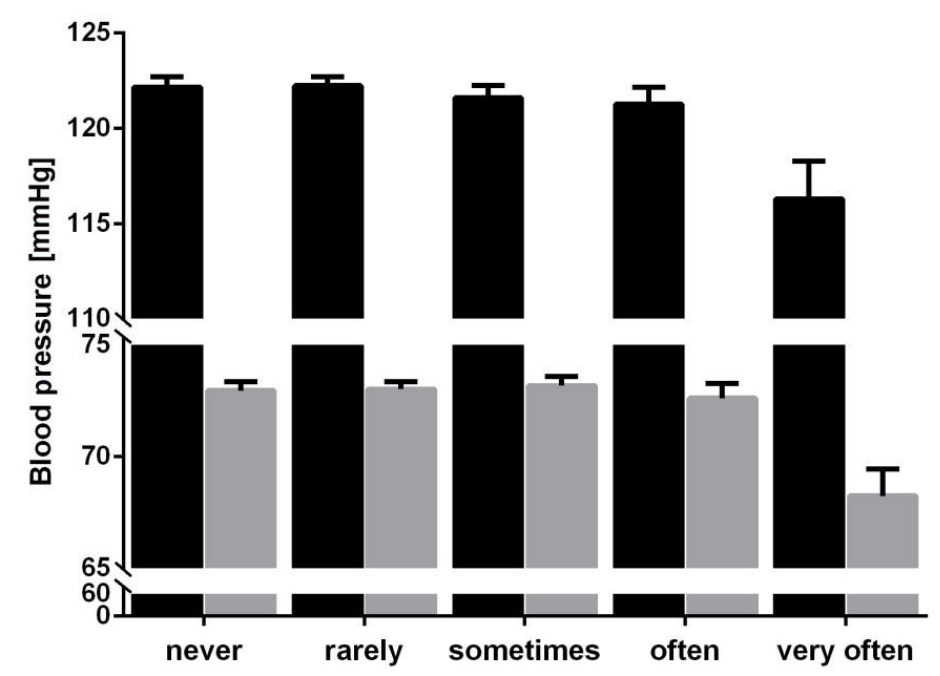

Item 11

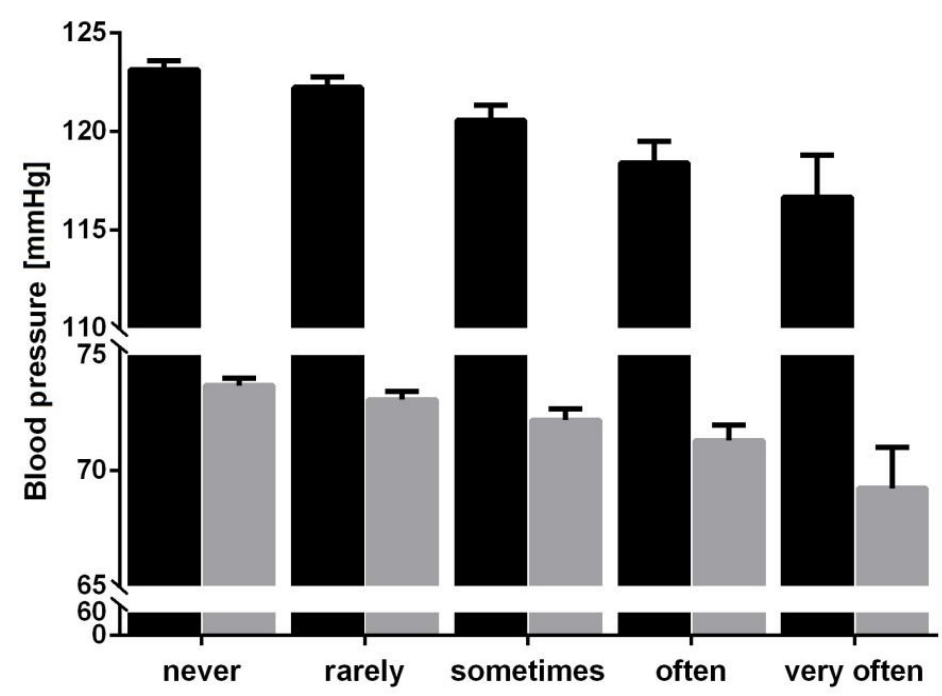

Item 8

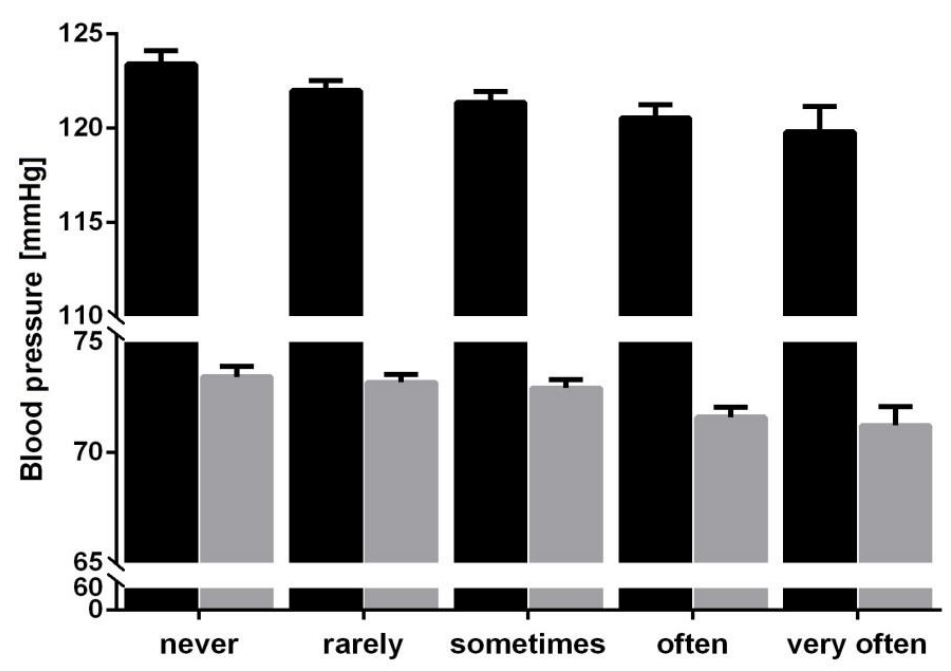

Item 10

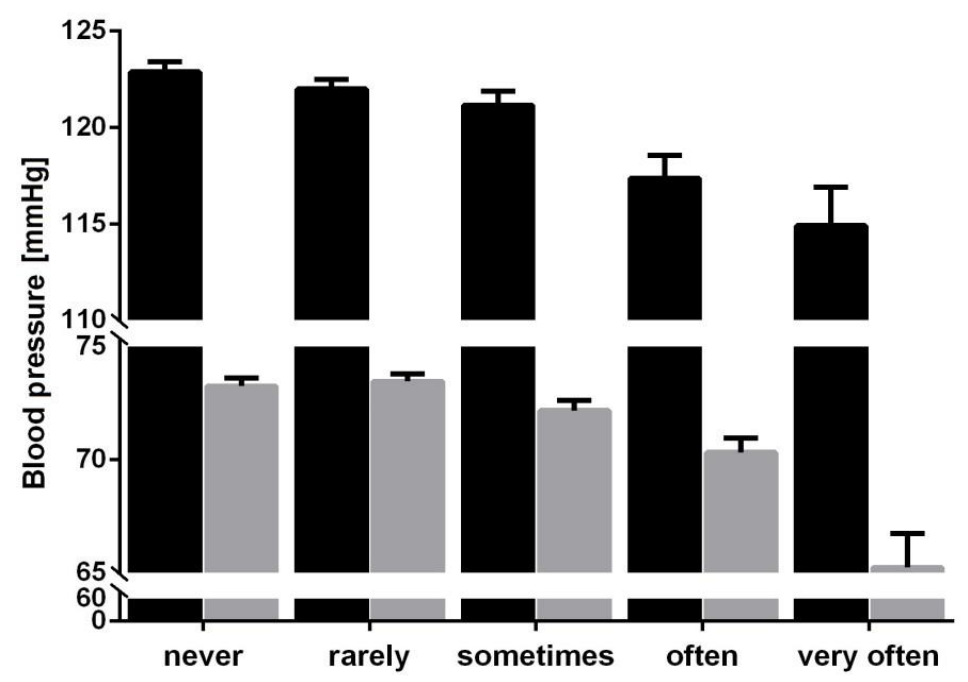

Item 12

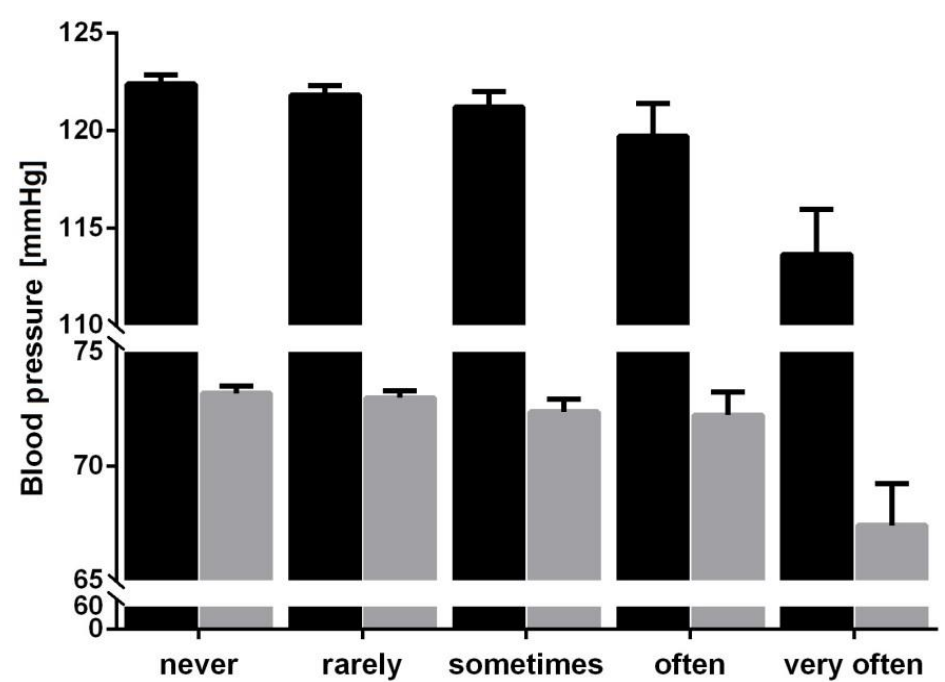

Figure 4: Histograms showing means and standard errors of systolic (black columns) and diastolic blood pressure (gray columns) classified according to the answers given for each item of TICS-SSCS. 


\subsection{Subgroups analyses}

The association between blood pressure and TICS-SSCS was tested in different subgroups. Bonferroni correction was also used for these subgroups analyses, so that the significance level was defined as 0.05 / the number of subgroups created for each variable.

When the study group was divided according to gender, the inverse relationship between TICS-SSCS and both systolic and diastolic blood pressure was nearly significant for women, while for men this relationship was not significant (Table 12). For age tertiles, the association was significant in the second tertile and nearly significant in the first tertile for systolic blood pressure, while for diastolic blood pressure the association was significant only in the second tertile. In the upper tertile, the significance was lost for both systolic and diastolic blood pressure.

The study population was also divided according to the blood pressure recordings into the group with normal blood pressure and the hypertension group, using a cut-off of $140 \mathrm{mmHg}$ for systolic and $90 \mathrm{mmHg}$ for diastolic blood pressure. For participants whose blood pressure values were within the normal range, the correlation remained significant for both systolic and diastolic blood pressure (Table 12), while for participants who met the definition of hypertension no significant associations were found.

The study cohort was dichotomized according to the values of PHQ-9 using a cut-off of 10 , which is frequently used for the identification of clinically relevant depression. The results showed that the associations were not significant in the high PHQ score group, while the associations were stable in the subgroup with normal PHQ-9 scores.

\begin{tabular}{|l|l|c|c|c|c|c|c|}
\hline & & \multicolumn{3}{|c|}{$\begin{array}{c}\text { Dependent variable: } \\
\text { Systolic blood pressure }\end{array}$} & \multicolumn{2}{c|}{$\begin{array}{c}\text { Dependent variable: } \\
\text { Diastolic blood pressure }\end{array}$} \\
\hline \multirow{2}{*}{ Gender } & Men & Estimate & SE & p-value & Estimate & SE & p-value \\
\cline { 2 - 8 } & Women & -0.045 & 0.053 & 0.396 & -0.046 & 0.034 & 0.173 \\
\hline
\end{tabular}




\begin{tabular}{|c|c|c|c|c|c|c|c|}
\hline \multirow{3}{*}{ Age } & First tertile & -0.114 & 0.054 & 0.035 & -0.060 & 0.033 & 0.072 \\
\hline & Second tertile & -0.217 & 0.050 & $<0.001$ & -0.155 & 0.038 & $<0.001$ \\
\hline & Third tertile & -0.151 & 0.082 & 0.066 & -0.078 & 0.049 & 0.115 \\
\hline \multirow{2}{*}{$\begin{array}{l}\text { PHQ-9 } \\
\text { score }\end{array}$} & $\begin{array}{l}\text { Non-depressed } \\
\text { subgroup }\end{array}$ & -0.150 & 0.041 & $<0.001$ & -0.090 & 0.028 & 0.001 \\
\hline & $\begin{array}{l}\text { Depressed } \\
\text { subgroup }\end{array}$ & -0.171 & 0.124 & 0.168 & -0.121 & 0.064 & 0.061 \\
\hline \multirow{2}{*}{$\begin{array}{l}\text { Blood } \\
\text { pressure }\end{array}$} & $\begin{array}{l}\text { Normal blood } \\
\text { pressure } \\
\text { subgroup }\end{array}$ & -0.145 & 0.030 & $<0.001$ & -0.091 & 0.024 & $<0.001$ \\
\hline & $\begin{array}{l}\text { High blood } \\
\text { pressure } \\
\text { subgroup }\end{array}$ & 0.114 & 0.070 & 0.103 & 0.055 & 0.060 & 0.356 \\
\hline
\end{tabular}

Table 12: Bivariate associations between systolic or diastolic blood pressure and TICS-SSCS in each indicated subgroup.

Using the same variables as in the final general linear models, the associations between TICS-SSCS and blood pressure were also tested in the above-mentioned subgroups which showed significant bivariate associations (Table 13). In the normal blood pressure group, the associations remained significant for both systolic and diastolic blood pressure, and in the non-depressed group, the associations remained significant for diastolic blood pressure and almost significant for systolic blood pressure. With respect to age tertiles, the correlations remained significant in the second age tertiles for diastolic blood pressure and almost significant for systolic blood pressure, and in the first age tertile a nearly significant association was observed only for diastolic blood pressure. 


\begin{tabular}{|l|l|c|c|c|c|c|c|}
\hline & & \multicolumn{2}{|c|}{$\begin{array}{c}\text { Dependent variable: } \\
\text { Systolic blood pressure }\end{array}$} & \multicolumn{2}{c|}{$\begin{array}{c}\text { Dependent variable: } \\
\text { Diastolic blood pressure }\end{array}$} \\
\hline & & Estimate & SE & p-value & Estimate & SE & p-value \\
\hline \multirow{2}{*}{ Age } & First tertile & -0.085 & 0.048 & 0.080 & -0.061 & 0.030 & 0.044 \\
\cline { 2 - 8 } & Second tertile & -0.124 & 0.055 & 0.024 & -0.114 & 0.042 & 0.007 \\
\hline $\begin{array}{l}\text { PHQ-9 } \\
\text { score }\end{array}$ & $\begin{array}{l}\text { Non-depressed } \\
\text { subgroup }\end{array}$ & -0.084 & 0.038 & 0.031 & -0.065 & 0.026 & 0.013 \\
\hline BP-value & $\begin{array}{l}\text { Normal blood } \\
\text { pressure subgroup }\end{array}$ & -0.086 & 0.029 & 0.003 & -0.069 & 0.022 & 0.002 \\
\hline
\end{tabular}

Table 13: Results from general linear models using either systolic or diastolic blood pressure as the dependent variable and TICS-SSCS as the independent variable after adjusting for age, sex, BMl, smoking habits, sport activity, alcohol consumption, living in partnership, caregiving strain, SES, OSLO3 and traffic intensity

\subsection{Analysis of the repeated measurements of blood pressure}

To test for differences among the three consecutive measurements of blood pressure, repeated measure ANOVA was computed. This type of general linear model is not available in the SPSS complex samples package, and thus, this analysis was performed using conventional statistics, including the weighting factor. When systolic blood pressure readings were entered as the repeated measure variable and stress categories were entered as the between subject variable, Mauchly's test for sphericity was significant $(p<0.001)$. Because the assumption of sphericity was violated, the Greenhouse-Geisser correction was used. The mean value of the first blood pressure reading was significantly higher than the means of the second and the third $(p<0.001)$. The between subject effect was significant $(p<0.001)$, while the interaction effect was not significant $(p=0.129)$.

When the readings of diastolic blood pressure were entered as the repeated measure variable and stress categories as the between subject variable, once again 
the Mauchly's test for sphericity was significant. Using the Greenhouse-Geisser correction, the change of diastolic blood pressure over time was significant, with the mean value of the first reading being higher than the second or third reading $(p<0.001)$. In addition to that, the between subject effect was significant $(p<0.001)$, but not the interaction effect between diastolic blood pressure measurements and stress categories $(p=0.323)$. The patterns of change in blood pressure values across the three consecutive measurements are graphically illustrated in Figure 5.

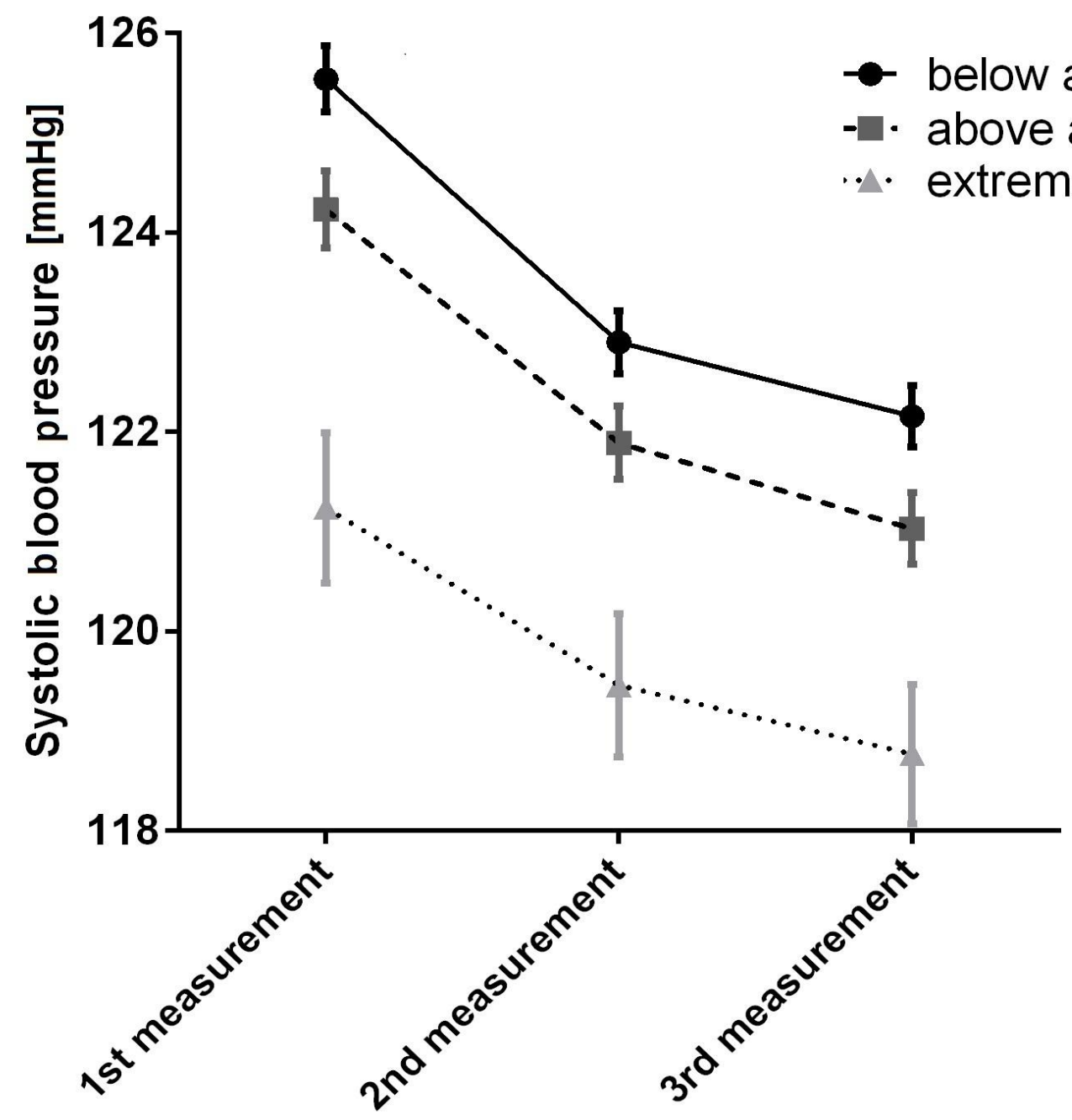


B

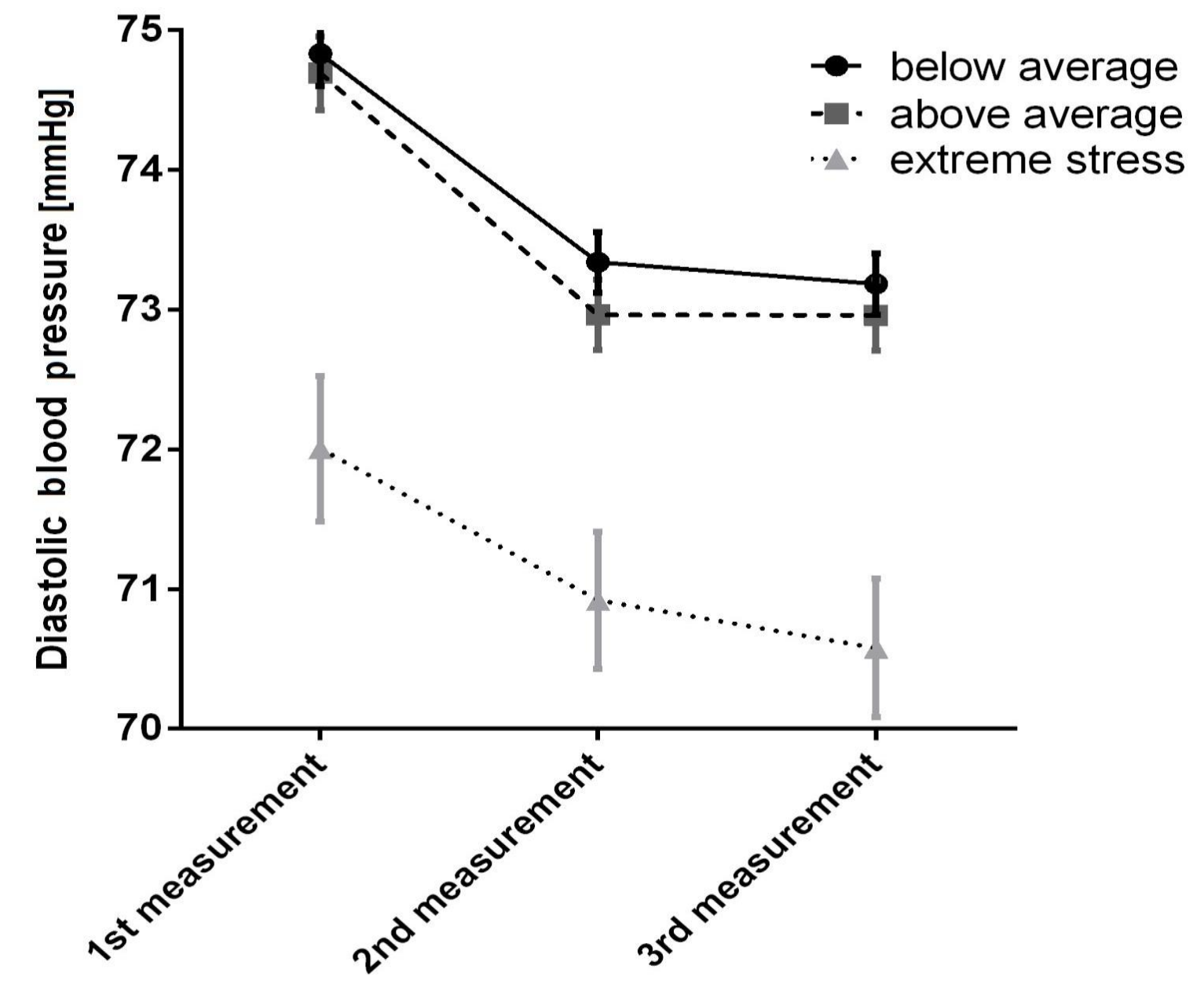

Figure 5: Changes in systolic (A) and diastolic (B) blood pressure across the three consecutive measurements shown as means and standard errors in the study cohort within the three stress categories

\subsection{Characteristics of excluded participants}

The study sample excluded participants who were taking antihypertensive medications. Next, the characteristics of those excluded participants (who were also employed) were compared with the study group using $t$ tests for continuous variables and Chi-square tests for categorical variables (Table 14). 


\begin{tabular}{|l|c|c|c|}
\hline & $\begin{array}{c}\text { Study group } \\
(\mathrm{n}=3352)\end{array}$ & $\begin{array}{c}\text { Participants with } \\
\text { antihypertensive } \\
\text { medication }(\mathrm{n}=630)\end{array}$ & p-value \\
\hline Age (years, mean \pm SE) & $39.8 \pm 0.24$ & $51.8 \pm 0.39$ & $<0.001$ \\
\hline Sex (Men \%) & $52.3 \pm 102$ & $54.9 \pm 2.6$ & 0.34 \\
\hline TICS-SSCS & $12.0 \pm 0.2$ & $11.6 \pm 0.4$ & 0.34 \\
\hline Systolic blood pressure & $121.9 \pm 0.3$ & $129.9 \pm 0.7$ & $<0.001$ \\
\hline Diastolic blood pressure & $72.9 \pm 0.2$ & $78 \pm 0.5$ & $<0.001$ \\
\hline
\end{tabular}

Table 14: Comparison between the two groups of participants without and with antihypertensive medication, demonstrating that participants in the latter group were significantly older and had higher systolic and diastolic blood pressure than the study group.

By applying the same set of variables as used in final multivariate analysis in the group of excluded participants, the observed inverse association between systolic or diastolic blood pressure and TICS-SSCS was no longer significant (Estimate $=-0.020$, $\mathrm{SE}=0.092, \mathrm{p}=0.828$ and Estimate $=-0.020, \mathrm{SE}=0.063, \mathrm{p}=0.751$, respectively). However, when the group of patients with hypertensive medication was combined with the study group, who were not taking antihypertensive drugs, the significant inverse correlation remained significant for both systolic (Estimate $=-0.083 \mathrm{SE}=0.033$, $\mathrm{p}=0.012$ ) and diastolic blood pressure (Estimate $=-0.066, \mathrm{SE}=0.022, \mathrm{p}=0.003$ ).

We also excluded participants who were not currently working, in order to guarantee the homogeneity of the study group. Unemployment could be associated with higher stress, but unfortunately in our study no measure of unemployment stress was available. We compared the basic characteristic of this group of participants (who were not taking antihypertensive medications also) with our study group (Table 15). 


\begin{tabular}{|l|c|c|c|}
\hline & $\begin{array}{c}\text { Study group } \\
(\mathrm{n}=3352)\end{array}$ & $\begin{array}{c}\text { Currently unemployed } \\
\text { participants }(\mathrm{n}=796)\end{array}$ & p-value \\
\hline Age (years, mean \pm SE) & $39.4 \pm 0.67$ & $39.3 \pm 0.24$ & 0.94 \\
\hline Sex (Men \%) & $52.3 \pm 1.2$ & $41.1 \pm 0.2$ & $<0.001$ \\
\hline TICS-SSCS & $12.0 \pm 0.18$ & $12.6 \pm 0.37$ & 0.16 \\
\hline Systolic blood pressure & $121.9 \pm 0.33$ & $120.7 \pm 0.55$ & 0.06 \\
\hline Diastolic blood pressure & $72.9 \pm 0.23$ & $71.9 \pm 0.37$ & 0.024 \\
\hline
\end{tabular}

Table 15: Comparison between the study sample and the group of participants who were currently unemployed. Participants in the unemployed group were more likely to be women and have lower blood pressure, but no differences in age and TICS-SSCS scores were found.

The inverse associations between TICS-SSCS and both systolic and diastolic blood pressure remained significant after combining this group to our study group (Estimate $=-0.094, \mathrm{SE}=0.031, \mathrm{p}=0.003$ and Estimate $=-0.064, \mathrm{SE}=0.020, \mathrm{p}=0.002$, respectively). When the analysis was applied on the unemployed group, the abovementioned associations between TICS-SSCS and blood pressure measurements lost their significance (Estimate $=-0.058, \mathrm{SE}=0.069, \mathrm{p}=0.401$ and Estimate $=0.018$, $\mathrm{SE}=0.042, p=0.673$ )

Missing data analysis regarding TICS-SSCS showed that, out of participants under 65 years of age, who were not on antihypertensive medication, only 154 participants did not fill out the questionnaire. These participants were older than those who completed the questionnaire ( 42.4 vs. 39.4 years, $p=0.032$ ), but there were no difference regarding the values of systolic and diastolic blood pressure, and also their sex distribution was similar to participants who completed the questionnaire. 


\section{Discussion}

This study, which is based on a large representative survey of the German population, addresses the question whether psychological stress is associated with higher levels of blood pressure. The results of this post-hoc analysis demonstrate that self-perceived stress was negatively associated with both systolic and diastolic blood pressure. These associations remained significant even after adjusting for a variety of confounders. No further significant associations were found in this sample between either systolic or diastolic blood pressure and the following variables: smoking behaviors, traffic intensity, caregiving, and living in partnership either cohabiting or married. However, an almost significant association between smoking habits and diastolic blood pressure was observed, with non-smoking participants having higher blood pressure and less stress perception as compared to smokers. This could be interpreted by the fact that smoking is more frequent among subjects with higher stress perception because of its lowering effect on their stress perception (Paperwalla et al. 2004). Alcohol consumption was independently and positively related to systolic blood pressure which is in line with numerous reports from the literature showing a relationship between excessive ethanol intake and elevated blood pressure in population-based samples (Marchi et al. 2014). Significant and negative association was observed between sport activity and diastolic but not systolic blood pressure; similar reports can be found in the literature (Stewart et al. 2005).

Subgroups analyses revealed that non-depressed, younger women with nonhypertensive blood pressure readings and low stress perception represent the main group of participants responsible for the observed association between blood pressure and self-perceived stress. We also investigated the patterns of blood pressure change over the three consecutive measurements, which showed the expected decline in both systolic and diastolic blood pressure readings. However, no significant effects of stress categories on these patterns were observed.

These findings are in accordance with the literature linking stress perception to the development of hypertension, in which controversial results were reported depending on the way stress or stress perception was assessed (Nyklícek et al. 1996). In their review, Nyklícek and colleagues cited clinical studies demonstrating that the same stressor was associated with blood pressure in different directions depending on how 
it was measured. For example, the authors discussed a study, in which hypertension was more prevalent in crowded areas, while at the same time hypertensive patients in these areas reported their lives to be less stressful compared to people living in less crowded areas. In another study about occupational stress, Greiner and colleagues reported that objectively measured job stress (observer-based stress) showed high association with the level of blood pressure, while self-reported stress showed an inverse association (Greiner et al. 2004). In another study by Fox and colleagues, higher job stress was associated with higher diastolic blood pressure even though self-reported stress showed an inverse correlation (Fox et al. 1993).

In our study, measures of stress were not significantly related with each other, so that people with higher occupational burden did not report their lives to be more stressful than other participants. The inconsistent relationship between different stress levels and blood pressure seems to be affected by the way how stress is actually measured. TICS-SSCS is not an instrument for objective stressors, but rather measures the subjective assessment of chronic stress perceived by participants. This implies that stress perception itself does not simply reflect the level of exposure to stressors, but it represents the final result of a complex psychological process that is highly affected by individual differences and former experiences (McEwen 1998). These findings from the DEGS1 study confirm that stress is based on a multidimensional concept including both objective and subjective aspects as well as their complex interaction.

It is well established that the cardiovascular system modulates the perception of pain, and early reports demonstrated that hypertensive animals have lower pain perception (Dworkin et al. 1979; Friedman et al. 1984; Maixner et al. 1982). These observations were replicated in numerous studies suggesting that elevated blood pressure is playing an inhibitory role on pain perception. From these studies we know that hypertensive patients have higher pain threshold than individuals without hypertension, and even within the normal range higher blood pressure was associated with less pain sensitivity (France 1999). This effect is known as hypertension-induced hypoalgesia, and it was suggested that this phenomenon can be generalized to include stressors other than pain.

The inverse association between pain sensitivity and the level of blood pressure has long been studied. However, data derived from this accumulating literature are not 
entirely clear, and it was assumed that hypoalgesia, which is associated with higher blood pressure in normotensives, is part of an adaptive process or a pathophysiological mechanism at the level of the central nervous system which contributes to the development of hypertension (Rau and Elbert 2001). Three underlying mechanisms were suggested to play a role in this inverse relationship between blood pressure and pain perception, which are the baroreceptor reflex, endogenous opioid activity, and noradrenergic activity (Bruehl and Chung 2004).

The baroreceptor-mediated processes are extensively studied and they have been proposed as key elements in the learned hypertension theory (Rau and Elbert 2001). Baroreceptors respond to the level and changes of the tension of the arterial walls and transmit these information to the brain, thereby contributing to blood pressure regulation. The baroreceptors are located mainly in the walls of large vessels, such as the aortic arch and the carotid arteries, where they monitor the blood supply to the brain. Afferent information are transmitted via the vagal nerve and glossopharyngeal nerve to the nucleus of the solitary tract which is located in the medulla oblongata, and it is thought that the inhibitory effect of high blood pressure is produced through the connection of this nucleus with pain descending pathways.

The role of baroreceptors in the hypertension-induced hypoalgesia is supported by a large body of evidence: both direct electrical stimulation and pharmacological activation of the baroreceptors lead to less pain perception, while surgical denervation of baroreceptors reverses this association and can even cause hyperalgesia in normotensive animals (Bruehl and Chung 2004). Continuous elevation in blood pressure produces a persistent activation of baroreceptors which eventually leads to resetting the set-point required for stimulating baroreceptors at a higher level. These observations form the basis of the learned hypertension theory (Rau and Elbert 2001).

The generalizability of the above-mentioned negative correlation between blood pressure and pain perception to other physiological stressors was tested in studies in hypertensive patients, who were exposed to physical (painful) stressors and psychological stressors. It was found that women with hypertension had less pain perception and lower negative appraisal of psychological stressors, showing a positive correlation between pain perception and the appraisal of negative stressors (Nyklícek et al. 2001). These findings were significant in women but not in men. 
Similarly, in this post-hoc analysis of the DEGS1 study there is also an almost significant association between blood pressure and stress perception in women, but not in men. This gender difference in reporting stress and pain has been shown in numerous trials (al'Absi et al. 1999): women in general seem to have higher pain sensitivity and higher stress perception, and evidence suggests that the relationship between blood pressure and pain perception differs between men and women (al'Absi et al. 2002). In a recent study, it was found that women are usually reporting more stress, but no significant association could be found between stress and cardiovascular risk in women, while this association was obvious in men (Puustinen et al. 2010). These findings imply that sex differences in perceiving stress and in responding to it should be taken into consideration and warrant more investigations.

Another possible explanation for our results can be found in the emotional dampening hypothesis, which is an extension of the pain sensitivity-blood pressure connection. When participants were provided with positive or negative pictures and sentences as a part of an experimental task, hypertensive participants perceived not only negative affects less negatively but also positive statements were perceived less positively when compared with normotensive participants (McCubbin et al. 2011). Accordingly, the regulation of cardiovascular responses and the perception of psychological affects interfere with each other at the level of the central nervous system. In this respect, the observed link between cardiovascular control and the regulation of emotions should be viewed as part of a complex and multidirectional psychophysiological adaptation system which warrants further investigations. Emotional dampening as an effective biological adaptation mechanism for coping with chronic stress is involved in blood pressure elevation and may contribute to the development of hypertension. However, emotional dampening can also increase psychological stress, and thus can further increase blood pressure, for example, through emotionally inappropriate interactions with others, including family, friends, and co-workers (McCubbin et al. 2011; McCubbin et al. 2014).

In order to interpret the observed decline in systolic and diastolic blood pressure, we assume that the examination process could be considered as a weak stressful situation, keeping in mind that it was performed in an unfamiliar environment as a part of a comprehensive medical and psychological evaluation. This mild stressor may have raised blood pressure above a hypothetical baseline, and the following 
measurements captured the returning of blood pressure to its former level. In this perspective, the decline in blood pressure could be interpreted as a recovery after an initial reactivity to the stress accompanied with the examination in general and the blood pressure measurements in particular. In addition to the significant decline in blood pressure, the main effect of stress categories was significant for both systolic and diastolic blood pressure. And although the pattern of blood pressure decline in the extreme stress category as demonstrated in figure 5 seems to be different compared with the other two categories, the interaction effect, as mentioned before, was not significant for both systolic and diastolic blood pressure, meaning that stress level had no influence on the pattern of blood pressure changes over time in our sample.

Exaggerated reactivity is usually viewed as a risk factor for hypertension as many trials showed that it could predict the development of hypertension and cardiovascular disease (Menkes et al. 1989; Matthews et al. 1993; Matthews et al. 2004). However, many recent studies showed that both extremes of reactivity could be associated with negative health consequences (Lovallo et al. 2011). For example, blunted cardiovascular reactivity was found to be associated with higher prevalence of depression, more stress perception, and poorer self-reported health (Broadley et al. 2005; Carroll et al. 2007; Phillips 2011).

Our study has the strength that it was based on a large survey which was representative of the German population. Moreover, the statistical analysis was performed using the complex samples procedure of SPSS, which took into consideration the stratified and clustered sampling as well as using the weighting factor in order to insure the representativity. Because DEGS1 is the first wave of the health monitoring program in adults conducted by the Robert Koch Institute, the results found in this post-hoc study can be reassessed in upcoming waves, as a part of a trend analysis.

Blood pressure measurements were performed following a standardized protocol. Using the average of the second and third measurements as the value of blood pressure helped to avoid false high values of blood pressure which could be caused by the white-coat effect. Using this value is in line with the observation that when a series of blood pressure measurements is performed the first one is usually the highest (Pickering et al. 2005). This procedure follows the recommendation of the 
seventh committee of hypertension that blood pressure should be measured at least two times in the same visit. It is also required that these readings should be replicated in two or more visits to confirm the diagnosis of hypertension, but this requirement is hard to be fulfilled in epidemiologic studies.

Excluding participants who were taking antihypertensive medications allowed for better reliability of the results as the effects of these medications on blood pressure are excluded. Different studies have linked antihypertensive medications such as beta-blockers to a higher prevalence of depressive symptoms (Luijendijk et al. 2011), implying possible effects of these medications on mental health, which could influence the perception of stress. Awareness of hypertension was also reported to interfere with the observed relationship between hypertension and stress (Nyklícek et al. 1996). However, it should be mentioned that there are other medications that could influence the level of blood pressure such as antidepressants and they were not excluded in this analysis. The parameter used for assessing perceived stress is based on well-validated instruments which cover a wide range of chronic stressors. The job index was designed specifically for Germany and was shown to be of high significance in predicting different diseases (Santi et al. 2013).

Our study has also several limitations as it is based on a cross-sectional survey which enables only for a snap shot impression about the association and does not allow drawing any conclusions about underlying causal pathways. Additionally, the survey was not designed specifically for the purpose of this study. Further information about some of the well-known hypertension risk factors were not available, such as salt intake, calcium intake, vitamin D serum levels, as well as information about ethnicity and family history of hypertension. Providing data about these risk factors would have been highly beneficial in analyzing the role of stress in the development of high blood pressure. Adding them to the final models would give higher reliability to the association observed between self-reported stresses or would possibly change it. Another limitation is that only participants younger than 65 years of age were included, and older participants who were not provided with TICS-SSCS might have different associations between stress and blood pressure levels.

Some of the variables used for estimating stress related to social circumstances in our analysis were not of high power, for example familial stand was simplified into two categories and there were no data available about the marital stress. Literature 
showed that women who have high marital stress were more susceptible to atherosclerosis compared with women who were in satisfying marriages, while single people were in the middle between these two categories (Gallo et al. 2003). For this reason, it is not possible to build solid conclusions about the link between familial stand and blood pressure based on this variable.

The variable concerned in caregiving strain comprised also two categories, which are people who were taking care of disabled relatives and those who were not. Therefore, the analysis was based on care giving status, rather than the stress induced by the caregiving itself. The literature showed that the association between caregiving strain and coronary artery disease depends on the appraisal of strain, subjects who reported no stress actually showed lower death rates compared with those who reported stress (Schulz and Beach 1999)

The effect sizes of the final models were relatively low, and the power is mainly attributed to factors other than stress, such as age, sex, and body-mass-index. However, self-reported stress remained negatively and significantly associated with both systolic and diastolic blood pressure levels, and these associations were independent from all other factors.

Studying the pattern of blood pressure decline across repeated measurements has many limitations as no ambulatory blood pressure monitoring was performed. This limitation makes it hard to identify the exact pattern of changes in blood pressure during the examination. There was no standard stressor that was used to define the recovery phase, and there was no reading that can be considered as the baseline.

Finally, it should be emphasized that the negative association between self-reported stress and blood pressure should be interpreted as only one aspect of a multidirectional regulation which most likely also includes other physiological parameters. Further research is required to decipher the pathways behind this finding. 


\section{Summary}

Objective: Psychosocial stressors have long been studied for their contribution to the development of hypertension, but their role remains controversial. In this post-hoc analysis of the nationwide German Health Interview and Examination Survey for Adults (DEGS1), the relationship of objectively measured stressors and self-reported stressors with blood pressure was studied. Methods: The study sample comprised 3,352 participants younger than 65 years old, who were currently employed and not taking antihypertensive medication. The recently developed occupational Overall Job Index was used for assessing work-related stress, and self-perceived chronic stress was measured using the Trier Inventory for the Assessment of Chronic Stress screening scale (TICS-SSCS). Results: Using bivariate tests, self-reported stress as measured by TICS-SSCS showed significant and negative association with both systolic (Estimate $=-0.16$, standard error $[S E]=0.03, p<0.001$ ) and diastolic blood pressure (Estimate $=-0.10, S E=0.02, p<0.001$ ), while the Overall Job Index showed positive significant association for both systolic (Estimate $=0.44, S E=0.11, p<0.001$ ) and diastolic blood pressure, respectively (Estimate $=0.20, \mathrm{SE}=0.07, \mathrm{p}=0.005$ ). After adjustment for age, sex, and body-mass-index, the TICS-SSCS remained significantly related to systolic and diastolic blood pressure, but the Overall Job Index did not. When further covariables were added to the regression models including alcohol consumption, smoking behaviors, physical activity, traffic intensity, socioeconomic status, social support, caregiving and living in partnership, the TICS-SSCS relationship with both systolic and diastolic blood pressure again remained significant $(p=0.007$ and $p=0.001)$. Conclusions: In a large and representative German study, we found that higher perceived stress was associated with lower blood pressure levels, while the objective stressors studied in this analysis were not correlated with blood pressure. This finding suggests that stress can influence blood pressure through different pathways, and that the perception of stress is linked to blood pressure regulation via complex physiological mechanisms. 


\subsection{Zusammenfassung}

Objektiv: Psychosoziale Stressoren wurden seit langem für ihren Beitrag zur Entwicklung einer arteriellen Hypertonie untersucht, aber ihre Rolle dabei bleibt umstritten. In dieser Post-hoc-Analyse der bundesweiten Studie zur Gesundheit Erwachsener in Deutschland (DEGS1) wurden die Beziehungen von objektiv gemessenen Stressoren und selbst berichtetem Stresslevel auf den Blutdruck bestimmt. Methoden: Die Stichprobe der Studie umfasste 3352 Teilnehmer, die jünger als 65 Jahre alt waren, und derzeit in einem Beschäftigungsverhältnis standen und keine antihypertensive Medikation einnahmen. Der neu entwickelte Overall-JobIndex wurde zur Bewertung des arbeitsrelevanten Stressniveaus verwendet und der selbst wahrgenommene chronische Stress mit der Trierer Inventar zur Erfassung von chronischem Stress Screening-Skala (TICS-SSCS) gemessen. Ergebnisse: Bivariate Tests zeigten signifikante und negative Assoziationen zwischen dem durch TICS-SSCS gemessenen, selbst berichteten Stress mit dem systolischen $($ Schätzer = $-0,16$, Standardfehler $[S E]=0,03, p<0,001$ ) bzw. diastolischen Blutdruck (Schätzer = $-0.10, \mathrm{SE}=0,02, p<0,001$ ), während der Overall-Job-Index positive signifikante Assoziationen für systolischen (Schätzer $=0,44, \mathrm{SE}=0,11, p<0,001$ ) und diastolischen Blutdruck aufwies (Schätzer $=0,20, S E=0,07, p=0,005$ ). Nach Adjustierung für Alter, Geschlecht und Body-Mass-Index blieb TICS-SSCS signifikant mit systolischem und diastolischem Blutdruck assoziiert, nicht aber mit dem OverallJob-Index. Als Alkoholkonsum, Raucherstatus, körperliche Aktivität, Verkehrsdichte, sozioökonomischer Status, soziale Unterstützung, Pflege von Angehörigen und Leben in Partnerschaft als weitere Kovariablen zu den vorherigen Modellen zugegeben wurden, blieb TICS-SSCS weiterhin mit systolischem und diastolischem Blutdruck assoziiert ( $p=0,007$ und $p=0,001)$. Schlussfolgerungen: In einer großen und repräsentativen deutschen Studie wurde festgestellt, dass ein höher wahrgenommenes Stressniveau mit niedrigem Blutdruck assoziiert ist, während die in dieser Analyse untersuchten objektiven Stressfaktoren nicht signifikant mit Blutdruck korreliert waren. Diese Ergebnisse deuten darauf, dass Stress den Blutdruck auf verschiedenen Wegen beeinflusst und dass die Wahrnehmung von Stress das Ergebnis einer komplexen physiologischen Reaktionsantwort ist, die die Regulierung des Blutdrucks einschließt. 


\section{Appendix}

Questions of Trier Inventory for the Assessment of Chronic Stress screening scale (TICS-SSCS):

Item 1: Befürchtung etwas Unangenehmes passiert i.d.I. 3 Mon.

Item 2: Sorgenvolle Gedanken i.d.I. 3 Mon.

Item 3: Vergebliche Bemühung um Anerkennung i.d.I. 3 Mon.

Item 4: Sorgen wachsen über den Kopf i.d.I. 3 Mon.

Item 5: Trotz Bemühung keine Anerkennung mit Arbeit i.d.I. 3 Mon.

Item 6: Erwartete Leistung nicht erfüllt i.d.I. 3 Mon.

Item 7: Ständige Sorgen i.d.I. 3 Mon.

Item 8: Zu viele Verpflichtungen i.d.I. 3 Mon.

Item 9: Arbeit wächst über den Kopf i.d.I. 3 Mon.

Item 10: Befürchtung Aufgaben nicht erfüllen zu können i.d.I. 3 Mon.

Item 11: Erfahrung zu viel zu tun zu haben i.d.I. 3 Mon.

Item12: Verantwortung für Andere wird zur Last i.d.I. 3 Mon.

Possible answers:

0) Nie 1) selten 2) manchmal 4) häufig 5) sehr häufig 


\section{References}

al'Absi M, Buchanan TW, Marrero A, Lovallo WR (1999): Sex differences in pain perception and cardiovascular responses in persons with parental history for hypertension. Pain $\underline{83}, 331-338$

al'Absi M, Petersena K, Wittmersc L (2002): Adrenocortical and hemodynamic predictors of pain perception in men and women. Pain $\underline{96}, 197-204$

Bao AM, Meynen G Swaab DF (2008): The stress system in depression and neurodegeneration: focus on the human hypothalamus. Brain Res Rev $\underline{57}, 531-553$

Beaglehole R, Bonita R, Horton R, Adams C, Alleyne G, Asaria P, Baugh V, Bekedam H, Billo N, Casswell S, et al. Lancet NCD Action Group; NCD Alliance. (2011): Priority actions for the non-communicable disease crisis. Lancet $\underline{377}$, 14381447

Berendes A, Meyer T, Hulpke-Wette M, Herrmann-Lingen C (2013): Association of elevated blood pressure with low distress and good quality of life: results from the nationwide representative German Health Interview and Examination Survey for Children and Adolescents. Psychosom Med 75, 422-428

Bøen H, Dalgard OS, Bjertness E (2012): The importance of social support in the associations between psychological distress and somatic health problems and socioeconomic factors among older adults living at home: a cross sectional study. BMC Geriatrics $\underline{12}$, e27

Broadley AJ, Freneaux MP, Moskvina V, Jones CJ, Korszun A (2005): Baroreflex sensitivity is reduced in depression. Psychosom Med $\underline{67}, 648-651$

Bruehl, S, Chung OY (2004): Interactions between the cardiovascular and pain regulatory systems: an updated review of mechanisms and possible alterations in chronic pain. Neurosci Biobehav Rev 28, 395-414

Burgaz A, Orsini N, Larsson SC, Wolk A (2011): Blood 25-hydroxyvitamin D concentration and hypertension: a meta-analysis. J Hypertens $\underline{29}$, 636-645

Busch MA, Maske UE, Ryl L, Schlack R, Hapke U (2013): Prevalence of depressive symptoms and diagnosed depression among adults in Germany: Results 
of the German Health Interview and Examination Survey for Adults (DEGS1). Bundesgesundheitsblatt Gesundheitsforschung Gesundheitsschutz ㅌ6, 733-739

Carnethon MR, Evans NS, Church TS, Lewis CE, Schreiner PJ, Jacobs DR Jr, Sternfeld B, Sidney S (2010): Joint associations of physical activity and aerobic fitness on the development of incident hypertension: coronary artery risk development in young adults. Hypertension $\underline{56}$, 49-55

Carroll D, Phillips A, Hunt K, Der G (2007): Symptoms of depression and cardiovascular reactions to acute psychological stress: evidence from a population study. Biol Psychol $\underline{75}, 68-74$

Carson AP, Howard G, Burke GL, Shea S, Levitan EB, Muntner P (2011): Ethnic differences in hypertension incidence among middle-aged and older adults: the multiethnic study of atherosclerosis. Hypertension $\underline{57}, 1101-1107$

Chobanian AV, Bakris GL, Black HR, Cushman WC, Green LA, Izzo JL Jr; Jones DW, Materson BJ, Oparil S, Wright JT Jr, et al. National Heart, Lung, and Blood Institute Joint National Committee on Prevention, Detection, Evaluation, and Treatment of High Blood Pressure; National High Blood Pressure Education Program Coordinating Committee (2003): The Seventh Report of the Joint National Committee on Prevention, Detection, Evaluation, and Treatment of High Blood Pressure: the JNC 7 report. JAMA 289, 2560-2572

Chrousos GP (2009): Stress and disorders of the stress system. Nat Rev Endocrinol $\underline{5}, 374-381$

Cook NR, Cohen J, Hebert PR, Taylor JO, Hennekens CH (1995): Implications of small reductions in diastolic blood pressure for primary prevention. Arch Intern Med $\underline{155}, 701-709$

Dalgard OS, Dowrick C, Lehtinen V, Vazquez-Barquero JL, Casey P, Wilkinson G, Ayuso-Mateos JL, Page H, Dunn G, ODIN Group (2006): Negative life events, social support and gender difference in depression: a multinational community survey with data from the ODIN study. Soc Psychiatry Psychiatr Epidemiol 41, 444-451

Dampney RA (1994): Functional organization of central pathways regulating the cardiovascular system. Physiol Rev $\underline{74}, 323-364$ 
Dworkin BR, Filewich RJ, Miller NE, Craigmyle N, Pickering TG (1979): Baroreceptor activation reduces reactivity to noxious stimulation: implications for hypertension. Science 205, 1299-1301.

Forman JP, Choi H, Curhan GC (2009): Fructose and vitamin C intake do not influence risk for developing hypertension. J Am Soc Nephrol $\underline{20}$, 863-871

Fox ML, Dwyer DJ, Ganster DC (1993): Effects of stressful job demands and control on physiological and attitudinal outcomes in a hospital setting. Acad Manage $\mathrm{J} 36$, 289-318

France C (1999): Decreased pain perception and risk for hypertension: Considering a common physiological mechanism. Psychophysiology $\underline{36}, 683-692$

Frasure-Smith N, Lesperance F, Gravel G, Masson A, Juneau M, Talajic $M$, Bourassa MG (2000): Social support, depression, and mortality during the first year after myocardial infarction. Circulation 101, 1919-1924

Friedman R, Murphy D, Persons W, McCaughran JA Jr (1984): Genetic predisposition to hypertension, elevated blood pressure and pain sensitivity: a functional analysis. Behav Brain Res 12, 75-79

Gallo LC, Troxel WM, Kuller LH, Sutton-Tyrrell K, Edmundowicz D, Matthews KA (2003): Marital status, marital quality, and atherosclerotic burden in postmenopausal women. Psychosom Med $\underline{65}$, 952-962

Gianaros PJ, Onyewuenyi IC, Sheu LK, Christie IC, Critchley HD (2012): Brain systems for baroreflex suppression during stress in humans. Hum Brain Mapp $\underline{33}$, 1700-1716

Gößwald A, Lange M, Dölle R, Hölling H (2013): The first wave of the German Health Interview and Examination Survey for Adults (DEGS1): Recruitment of participants, fieldwork, and quality assurance. Bundesgesundheitsblatt Gesundheitsforschung Gesundheitsschutz $\underline{56}, 611-619$

Greiner BA, Krause N, Ragland D, Fisher JM (2004): Occupational stressors and hypertension: a multi-method study using observer-based job analysis and selfreports in urban transit operators. Soc Sci Med $\underline{59}, 1081-1094$ 
Ha V, Sievenpiper JL, de Souza RJ, Chiavaroli L, Wang DD, Cozma A, Mirrahimi A, Yu ME, Carleton AJ, Dibuono M, et al. (2012): Effect of fructose on blood pressure: a systematic review and meta-analysis of controlled feeding trials. Hypertension $\underline{59}$, 787-795

Hapke U, von der Lippe E, Gaertner B (2013): Alcohol consumption, at-risk and heavy episodic drinking with consideration of injuries and alcohol-specific medical advice: results of the German Health Interview and Examination Survey for Adults (DEGS1). Bundesgesundheitsblatt Gesundheitsforschung Gesundheitsschutz 므, 809-813

He FJ, MacGregor GA (2010): Reducing population salt intake worldwide: from evidence to implementation. Prog Cardiovasc Dis $\underline{52}, 363-382$

Henry JP, Liu YY, Nadra WE, Qian CG, Mormede P, Lemaire V, Ely D, Hendley ED (1993): Psychosocial stress can induce chronic hypertension in normotensive strains of rats. Hypertension 21, 714-723

Hildrum B, Mykletun A, Stordal E, Bjelland I, Dahl AA, Holmen J (2007): Association of low blood pressure with anxiety and depression: the Nord-Trøndelag Health Study. J Epidemiol Community Health $\underline{61}, 53-58$

Jalal DI, Smits G, Johnson RJ, Chonchol M (2010): Increased fructose associates with elevated blood pressure. J Am Soc Nephrol 21, 1543-1549

Kamtsiuris P, Lange M, Hoffmann R, Schaffrath Rosario A, Dahm S, Kuhnert R, Kurth BM (2013): The first wave of the German Health Interview and Examination Survey for Adults (DEGS1): Sampling design, response, weighting, and representativeness. Bundesgesundheitsblatt Gesundheitsforschung Gesundheitsschutz $\underline{56}, 620-630$

Kearney PM, Whelton M, Reynolds K, Muntner P, Whelton PK, He J (2005): Global burden of hypertension: analysis of worldwide data. Lancet $\underline{365}, 217-223$

Kneipp SM, Yarandi HN (2002): Complex sampling designs and statistical issues in secondary analysis. West J Nurs Res $\underline{24}, 552-566$ 
Knopf H, Grams D (2013): Medication use of adults in Germany: results of the German Health Interview and Examination Survey for Adults (DEGS1). Bundesgesundheitsblatt Gesundheitsforschung Gesundheitsschutz 트, 868-877

Knox SS, Uvnäs-Moberg K (1998): Social isolation and cardiovascular disease: an atherosclerotic pathway? Psychoneuroendocrinology $\underline{23}, 877-890$

Krantz DS, Manuck SB (1984): Acute psychophysiologic reactivity and risk of cardiovascular disease: a review and methodologic critique. Psychol Bull 96, 435-464

Kroenke K, Spitzer RL, Williams JB (2001): The PHQ-9: Validity of a brief depression severity measure. J Gen Intern Med 16, 606-613

Kroll LE (2011): Konstruktion und Validierung eines allgemeinen Index für die Arbeitsbelastung in beruflichen Tätigkeiten anhand von ISCO-88 und KIdB-9. Methoden-Daten-Analysen $\underline{5}, 63-90$

Krug S, Jordan S, Mensink GB, Müters S, Finger J, Lampert T (2013): Physical activity: results of the German Health Interview and Examination Survey for Adults (DEGS1). Bundesgesundheitsblatt Gesundheitsforschung Gesundheitsschutz $\underline{56}$, $765-771$

Lampert T, von der Lippe, E, Müters S (2013a): Prevalence of smoking in the adult population of Germany: results of the German Health Interview and Examination Survey for Adults (DEGS1). Bundesgesundheitsblatt Gesundheitsforschung Gesundheitsschutz $\underline{56}, 802-808$

Lampert T, Kroll LE, von der Lippe E, Müters S, Stolzenberg H (2013b): Socioeconomic status and health: results of the German Health Interview and Examination Survey for Adults (DEGS1). Bundesgesundheitsblatt Gesundheitsforschung Gesundheitsschutz $\underline{56}, 814-821$

Lawes CM, Vander Hoorn S, Rodgers A (2008): International Society of Hypertension, Global burden of blood-pressure-related disease 2001. Lancet $\underline{371}$, 1513-1518

Lee S, Colditz GA, Berkman LF, Kawachi I (2003): Caregiving and risk of coronary heart disease in U.S. women: a prospective study. Am J Prev Med 24, 113-119 
Lewington S, Clarke R, Qizilbash N, Peto R, Collins R (2002): Prospective Studies Collaboration. Age-specific relevance of usual blood pressure to vascular mortality: a meta-analysis of individual data for one million adults in 61 prospective studies. Lancet $\underline{360}, 1903-1913$

Linden W, Earle TL, Gerin W,\& Christenfeld N (1997): Physiological stress reactivity and recovery: conceptual siblings separated at birth? J Psychosom Res $\underline{42}$, 117-135

Lovallo WR (2011): Do low levels of stress reactivity signal poor states of health? Biological Psychology $\underline{86}, 121-128$

Luijendijk HJ, van den Berg JF, Hofman A, Tiemeier H, Stricker BH (2011): $\beta$ blockers and the risk of incident depression in the elderly. J Clin Psychopharmacol $\underline{31}, 45-50$

Lynch J, Kaplan GA, Salonen R, Cohen RD, Salonen JT (1995): Socio-economic status and carotid atherosclerosis. Circulation $\underline{92}, 1786-1792$

Lynch JW, Everson SA, Kaplan GA, Salonen R, Salonen JT (1998): Does low socio-economic status potentiate the effects of heightened cardiovascular responses to stress on the progression of carotid atherosclerosis? Am J Public Health $\underline{88}, 389$ 394

Maixner W, Touw KB, Brody MJ, Gebhart GF, Long JP (1982): Factors influencing the altered pain perception in the spontaneously hypertensive rat. Brain Res $\underline{237}$, 137-145

Marchi KC, Muniz JJ, Tirapelli CR (2014): Hypertension and chronic ethanol consumption: What do we know after a century of study? World J Cardiol $\underline{6}$, 283-294

Matthews KA, Woodall KL, Allen MT (1993): Cardiovascular reactivity to stress predicts future blood pressure status. Hypertension 22, 479-485

Matthews KA, Katholi $\mathrm{CR}$, McCreath $\mathrm{H}$, Whooley MA Williams DR, Zhu S, Markovitz JH (2004): Blood pressure reactivity to psychological stress predicts hypertension in the CARDIA study. Circulation $\underline{110}, 74-78$ 
McCubbin JA, Merritt MM, Sollers JJ3rd, Evans MK, Zonderman A, Lane RD, Thayer JF (2011): Cardiovascular-emotional dampening: the relationship between blood pressure and recognition of emotion. Psychosom Med $\underline{73}, 743-750$

McCubbin JA, Loveless JP, Graham JG, Hall GA, Bart RM, Moore DD, Merritt MM, Lane RD, Thayer JF (2014): Emotional dampening in persons with elevated blood pressure: Affect dysregulation and risk for hypertension. Ann Behav Med 47, 110-119

McEwen BS (1998): Protective and damaging effects of stress mediators. N Engl J Med $\underline{338}, 171-179$

Meng L, Chen D, Yang Y, Zheng Y, Hui R (2012): Depression increases the risk of hypertension incidence: a meta-analysis of prospective cohort studies. J Hypertens $\underline{30}, 842-851$

Menkes MS, Matthews KA, Krantz DS, Lundberg U, Mead LA, Qaqish B, Liang KY, Thomas CB, Pearson TA (1989): Cardiovascular reactivity to the cold pressor test as a predictor of hypertension. Hypertension 14, 524-530

Murray CJ, Vos T, Lozano R, Naghavi M, Flaxman AD, Michaud C, Ezzati M, Shibuya K, Salomon JA, Abdalla S, et al. (2012): Disability-adjusted life years (DALYs) for 291 diseases and injuries in 21 regions, 1990-2010: a systematic analysis for the Global Burden of Disease Study 2010. Lancet $\underline{380}$, 2197-2223

Neuhauser H, Thamm M, Ellert U (2013): Blood pressure in Germany 2008-2011: results of the German Health Interview and Examination Survey for Adults (DEGS1). Bundesgesundheitsblatt Gesundheitsforschung Gesundheitsschutz $\underline{56}, 795-801$

Nyklícek I, Vingerhoets JJ, Van Heck GL (1996): Hypertension and objective and self-reported stressor exposure: a review. J Psychosom Res $\underline{40}, 585-601$

Nyklícek I, Vingerhoets AJ, Van Heck GL (2001): Hypertension and appraisal of physical and psychological stressors. J Psychosom Res $\underline{50}$, 237-244

O'Brien E, Waeber B, Parati G, Staessen J, Myers MG (2001): Blood pressure measuring devices: recommendations of the European Society of Hypertension. BMJ $\underline{322}, 531-536$ 
Orth-Gomer K, Wamala SP, Horsten M, Schenck-Gustafsson K, Schneiderman N, Mittleman MA (2000): Marital stress worsens prognosis in women with coronary heart disease: the Stockholm Female Coronary Risk Study. JAMA 284, 3008-3014

Page GD, France CR (1997): Objective evidence of decreased pain perception in normotensives at risk for hypertension. Pain $\underline{73}, 173-180$

Paperwalla KN, Levin TT, Weiner J, Saravay SM (2004): Smoking and depression. Med Clin North Am $\underline{88}, 1483-1494$

Phillips AC (2011). Blunted cardiovascular reactivity relates to depression, obesity, and self reported health. Biol Psychol $\underline{86}, 106-113$

Pickering T (1999): Cardiovascular pathways: Socio-economic status and stress effects on Hypertension and cardiovascular function. Ann N Y Acad Sci $\underline{896}$, 262277

Pickering TG, Hall JE, Appel LJ, Falkner BE, Graves J, Hill MN, Jones DW, Kurtz T, Sheps SG, Roccella EJ (2005): Recommendations for blood pressure measurement in humans and experimental animals: Part 1: Blood pressure measurement in humans: A statement for professionals from the Subcommittee of Professional and Public Education of the American Heart Association Council on High Blood Pressure Research. Hypertension 45, 142-161

Puustinen PJ, Koponen H, Kautiainen H, Mäntyselkä P, Vanhala M (2010): Gender-specific association of psychological distress with cardiovascular risk scores. Scand J Prim Health Care $\underline{28}, 36-40$

Rau H, Elbert T (2001): Psychophysiology of arterial baroreceptors and the etiology of hypertension. Biol Psychol $\underline{57}, 179-201$

Rosengren A, Hawken S, Ounpuum S, Sliwa K, Zubaid, M; Almahmeed WA, Blackett KN, Sitthi-amorn C, Sato H, Yusuf S, INTERHEART investigators (2004): Association of psychosocial risk factors with risk of acute myocardial infarction in 11119 cases and 13648 controls from 52 countries (the INTERHEART study): casecontrol study. Lancet $\underline{364}, 953-962$ 
Rozanski A, Blumenthal JA, Kaplan J (1999): Impact of psychological factors on the pathogenesis of cardiovascular disease and implications for therapy. Circulation $\underline{99}, 2192-2217$

Rozanski A, Blumenthal JA, Davidson KW, Saab PG, Kubzansky L (2005): The epidemiology, pathophysiology, and management of psychosocial risk factors in cardiac practice: the emerging field of behavioral cardiology. J Am Coll Cardiol $\underline{45}$, $637-651$

Santi I, Kroll LE, Dietz A, Becher H, Ramroth H (2013): Occupation and educational inequalities in laryngeal cancer: the use of a job index. BMC Public Health $\underline{13}$, e1080

Sapira JD, Scheib ET, Moriarty R, Shapiro AP (1971): Differences in perception between hypertensive and normotensive populations. Psychosom Med $\underline{33}, 239-250$

Saylor J, Friedmann E, Lee HJ (2012): Navigating complex sample analysis using national survey data. Nurs Res $\underline{61}, 231-237$

Scheidt-Nave C, Kamtsiuris P, Gößwald A, Hölling H, Lange M, Busch MA, Dahm S, Dölle R, Ellert U, Fuchs J, et al. (2012): German health interview and examination survey for adults (DEGS). Design, objectives and implementation of the first data collection wave. BMC Public Health 12, e730

Schnall PL, Schwartz JE, Landsbergis PA, Warren K, Pickering TG (1998): A longitudinal study of job strain and ambulatory blood pressure: results from a threeyear follow-up. Psychosom Med $\underline{60}$, 697-706

Schulz R, Beach SR (1999) Caregiving as a risk factor for mortality: the Caregiver Health Effects Study. JAMA 282, 2215-2219

Seeman TE, Syme L (1987): Social networks and coronary artery disease: a comparison of the structure and function of social relations as predictors of disease. Psychosom Med 49, 341-354

de Simone G, Devereux RB, Chinali M, Roman MJ, Best LG, Welty TK, Lee ET, Howard BV (2006): Risk factors for arterial hypertension in adults with initial optimal blood pressure: the Strong Heart Study. Hypertension 47, 162-167 
Sparrenberger F, Cichelero FT, Ascoli AM, Fonseca FP, Weiss G, Berwanger O, Fuchs SC, Moreira LB, Fuchs FD (2009): Does psychosocial stress cause hypertension? A systematic review of observational studies. J Hum Hypertens $\underline{23}$, $12-19$

Stewart KJ, Bacher AC, Turner KL, Fleg JL, Hees PS, Shapiro EP, Tayback M, Ouyang $P$ (2005): Effect of exercise on blood pressure in older persons: a randomized controlled trial. Arch Intern Med $\underline{165}, 756-762$

Uno D, Uchino BN, Smith TW (2002): Relationship quality moderates the effect of social support given by close friends on cardiovascular reactivity in women. Int $\mathrm{J}$ Beh Med $\underline{9}, 243-262$

Victor RG, Systemic hypertension : mechanisms and diagnosis. In Bonow, RO; Mann DL, Zipes DP, Libby P (2012): Braunwald's Heart Disease A Textbook of cardiovascular Medicine. Elsevier Saunders, Philadelphia. 937-940

Victor, RG; Shafiq, MM (2008): Sympathetic neural mechanisms in human hypertension. Curr Hypertens Rep 10, 241-247

Wang NY, Young JH, Meoni LA, Ford DE, Erlinger TP, Klag MJ (2008): Blood pressure change and risk of hypertension associated with parental hypertension: the Johns Hopkins Precursors Study. Arch Intern Med 168, 643-648

Whelton PK, He J, Appel LJ, Cutler JA, Havas S, Kotchen TA, Roccella EJ, Stout R, Vallbona C, Winston MC, et al. National High Blood Pressure Education Program Coordinating Committee (2002): Primary prevention of hypertension: clinical and public health advisory from The National High Blood Pressure Education Program. JAMA $\underline{288}, 1882-1888$

White WB, Herbst T, Thavarajah S, Giacco S (2003): Clinical evaluation of the Trimline blood pressure cuffs with the Accutorr Plus Monitor. Blood Press Monit $\underline{8}$, $137-140$

Wood DL, Sheps SG, Eleback LR, Schirger A (1984): Cold pressor test as a predictor of hypertension. Hypertension $\underline{6}, 301-306$ 
Yan LL, Liu K, Matthews KA, Daviglus ML, Ferguson TF, Kiefe Cl (2003): Psychosocial factors and risk of hypertension: the Coronary Artery Risk Development in Young Adults (CARDIA) study. JAMA $\underline{290}, 2138-2148$ 


\section{Acknowledgment}

I would like to express my deep appreciation to my supervisor Prof. Dr. Thomas Meyer for his constant support and valuable advice. During my working with Professor Meyer I have learned a lot from him, how to analyze epidemiological data and how to interpret the results in a scientific and logical way, how to ask the right questions and how to organize my work to reach the answers. Professor Meyer has taught me to have new perspectives and how to process unexpected results to build new hypotheses and draw scientific conclusions.

Many thanks to Prof. Dr. Herrmann-Lingen for giving me this opportunity to do my medical dissertation in the Department of Psychosomatic Medicine and Psychotherapy and for his help and valuable scientific comments.

I also thank the responsible scientists at the Robert Koch Institute for allowing me to work on the DEGS1 data. In particular, I cordially thank Dr. Scheidt-Nave for her advice and her friendly support. I am also grateful to Dr. Neuhauser, Dr. Busch and Dr. Hapke, whose comments have helped to improve this work.

To all my colleagues thanks a lot for their encouragement and for the friendly work environment they created. 


\section{Curriculum vitae}

I, Lina Hassoun, was born in Latakia / Syria on 27.02.1983 as the second child of my parents, Ali Hassoun and Suuad Alkhateeb, in a family of four children.

During the period between 1997 and 2000, I studied in Suheel Abu Alshamlat high school, Latakia, and in the year 2000 I got my high school certificate with the grade 252/260. Afterwards, I was accepted in the Faculty of Medicine of Tishreen University, Latakia / Syria, and I received the license of Doctor (Bachelor degree) in Human Medicine in 2006 with the grade "very good" (79,3\%) after 12 semesters including a practical phase of 3 years.

In December 2006 I started my residency in neurology at the Hospitals of Damascus University. The residency lasted 5 years and consisted of two phases; two years in the internal medicine department and three years in the neurology department. In the

year 2012, I got the post-graduate studies certificate (Master degree) in Neurology with the grade "very good" $(83,1 \%)$. The title of my master thesis was as follows: "A comparison of three ways of conservative treatment of mild and moderate carpal tunnel syndrome on short and long term".

Between December 2011 and December 2013 I worked as a neurologist at the Alkalmoon University Hospital, where I also participated in training medical students in addition to my responsibilities in the clinic and the department of Neurology.

Since April 2014 I have started working on my medical thesis under the supervision of Prof. Dr. Thomas Meyer in the Department of Psychosomatic Medicine at the University of Goettingen, Germany, where I got a scholarship from the German Center for Cardiovascular Research. 


\section{Publications}

Hassoun L, Herrmann-Lingen C, Hapke U, Neuhauser H, Scheidt-Nave C, Meyer T. Association between chronic stress and blood pressure: findings from the German Health Interview and Examination Survey for Adults 2008-11, Psychosomatic Medicine (in press).

\section{Contribution to Conferences (Abstracts)}

Meyer T, Hassoun L, Hapke U, Neuhauser H, Scheidt-Nave C, Herrmann-Lingen C. (2015): Self-perceived chronic stress and blood pressure: Results from the German Health Interview and Examination Survey for Adults 2008-2011. American Psychosomatic Society 73rd Annual Meeting, Psychosomatic Medicine.

Herrmann-Lingen C, Hassoun L, Scheidt-Nave C, Meyer T (2014): Both resting blood pressure and "white-coat effect" inversely related to depressive symptoms and mental quality of life in a representative German population sample. Birmingham Cardiovascular Reactivity: The Effects of Psychological Stress on Health. 